MÜHELYTANULMÁNYOK

DISCUSSION PAPERS

MT-DP. 2004/23

\title{
NETWORK MARKETS AND \\ CONSUMER COORDINATION
}

\author{
ATTILA AMBRUS \\ ROSSELLA ARGENZIANO
}

Institute of Economics

Hungarian Academy of Sciences

Budapest 


\title{
NETWORK MARKETS AND CONSUMER COORDINATION
}

\author{
ATTILA AMBRUS \\ ROSSELLA ARGENZIANO
}


KTI/IE Discussion Papers 2004/23

Institute of Economics Hungarian Academy of Sciences

KTI/IE Discussion Papers are circulated to promote discussion and provoque comments. Any references to discussion papers should clearly state that the paper is preliminary. Materials published in this series may subject to further publication.

The paper was selected for the $4^{\text {th }}$ Budapest Summer Workshop for young economists, organised by the KTI/IE on 29-30 June 2004.

The Budapest Summer Workshops intend to bring together young economists with foreign $\mathrm{PhD}$ education, frequently still working or studying abroad.

\section{Network Markets and Consumer Coordination}

Authors: Attila AMBRUS, Department of Economics, Harvard University, Cambridge, MA 02138. E-mail: ambrus@ fas.harvard.edu

Rossella ARGENZIANO, Department of Economics, Yale University, New Haven, CT 06520-8268.

E-mail: rosa.argenziano@yale.edu

We would like to thank Dirk Bergemann, Bernard Caillaud, Gergely Csorba, Ulrich Doraszelvski, Erica Field, Drew Fudenberg, Dino Gerardi, Stephen Morris, Gábor Virág and seminar participants at Yale University, Harvard University, Olin School of Business, at the Conference on Two-Sided Markets organized by IDEI Toulouse and at the $31^{\text {st }}$ TPRC for comments and suggestions.

HU ISSN 1785-377X

ISBN 9639588245

Published by the Institute of Economics Hungarian Academy of Sciences, Budapest, 2004. With financial support from the Hungarian Economic Foundation 
The Publications of the Institute of Economics

BUDAPEST WORKING PAPERS

ON THE LABOUR MARKET

BUDAPESTI

MUNKAGAZDASÁGTANI FÜZETEK

\begin{tabular}{|c|c|c|}
\hline BWP 2003/1 & Ágnes Hárs & $\begin{array}{l}\text { Channeled East-West labour migration in the frame of bilateral } \\
\text { agreements }\end{array}$ \\
\hline BWP 2003/2 & Galasi Péter & $\begin{array}{l}\text { Munkanélküliségi indikátorok és az állásnélküliek munkaerő-piaci } \\
\text { kötődése }\end{array}$ \\
\hline BWP 2003/3 & Károly Fazekas & $\begin{array}{l}\text { Effects of foreign direct investment on the performance of local } \\
\text { labour markets - The case of Hungary }\end{array}$ \\
\hline BWP 2003/4 & Péter Galasi & Estimating wage equations for Hungarian higher-education graduates \\
\hline BWP 2003/5 & Péter Galasi & Job-training of Hungarian higher-education graduates \\
\hline BWP 2003/6 & $\begin{array}{l}\text { Gábor Kertesi and } \\
\text { János Köllő }\end{array}$ & $\begin{array}{l}\text { The Employment Effects of Nearly Doubling the Minimum Wage - } \\
\text { The Case of Hungary }\end{array}$ \\
\hline BWP 2003/7 & $\begin{array}{l}\text { Nemes-Nagy J. - } \\
\text { Németh N. }\end{array}$ & $\begin{array}{l}\text { A "hely" és a "fej". A regionális tagoltság tényezői az ezredfor- } \\
\text { duló Magyarországán }\end{array}$ \\
\hline BWP 2003/8 & Júlia Varga & $\begin{array}{l}\text { The Role of Labour Market Expectations and Admission Probabilities } \\
\text { in Students' Application Decisions on Higher Education: the case of } \\
\text { Hungary }\end{array}$ \\
\hline BWP 2004/1 & Gábor Kertesi & The Employment of the Roma - Evidence from Hungary \\
\hline BWP 2004/2 & Kézdi Gábor & $\begin{array}{l}\text { Az aktív foglalkoztatáspolitikai programok hatásvizsgálatának mód- } \\
\text { szertani kérdései }\end{array}$ \\
\hline BWP 2004/3 & Galasi Péter & Valóban leértékelődtek a felsőfokú diplomák? \\
\hline BWP 2004/4 & Galasi Péter & $\begin{array}{l}\text { Túlképzés, alulképzés és bérhozam a magyar munkaerőpiacon } \\
\text { 1994-2002 }\end{array}$ \\
\hline BWP 2004/5 & István R. Gábor & Capitalist firm vis-à-vis with trade union, versus producer cooperative \\
\hline BWP 2004/6 & $\begin{array}{l}\text { Bódis L.-J. Mickle- } \\
\text { wright-Nagy Gy. }\end{array}$ & $\begin{array}{l}\text { A munkanélküli ellátás indokoltsági feltételeinek érvényesítése: em- } \\
\text { pirikus vizsgálat az elhelyezkedési készség ellenőrzésének hatásairól }\end{array}$ \\
\hline
\end{tabular}

RESEARCH IN LABOUR ECONOMICS

(Volumes based on conferences organised by KTK/IE and the Labour Science Committee HAS)

Munkaerőpiac és regionalitás az átmenet időszakában. Budapest, 1998.

A munkaügyi kapcsolatok rendszere és a munkavállalók helyzete. Budapest, 2000.

Ed.: K. Fazekas

Oktatás és munkaerőpiaci érvényesülés. Budapest, 2001.

Ed.: J. Koltay

A felzárkózás esélyei - Munkapiaci látlelet a felzárkózás küszöbén. Budapest, 2003. Ed.: Gy. Kővári

Ed.: A. Semjén

LABOUR MARKET YEARBOOKS

Munkaeröpiaci tükör - 2000. Budapest, 2000.

Ed.: K. Fazekas

Munkaeröpiaci tükör - 2001. Budapest, 2001.

Ed.: K. Fazekas

Munkaerőpiaci tükör - 2002. Budapest, 2002.

Ed.: K. Fazekas

Munkaeröpiaci tükör - 2003. Budapest, 2003.

Ed.: K. Fazekas

Munkaeröpiaci tükör - 2004. Budapest, 2004.

The Hungarian Labour Market - Review and Analysis, 2002. Bp., 2002

Eds.: K. Fazekas, J. Varga

The Hungarian Labour Market - Review and Analysis, 2003. Bp., 2003

Eds.: K. Fazekas, J. Koltay

Eds.: K. Fazekas, J. Koltay

The Hungarian Labour Market - Review and Analysis, 2004. Bp., 2004 Eds.: K. Fazekas, J. Koltay, Zs. Gergely

Papers can be downloaded from the homepage of the Institute of Economics http://econ.core.hu 


\begin{tabular}{|c|c|c|}
\hline MT-DP. 2004/1 & Attila HAVAS & $\begin{array}{l}\text { Assessing the Impact of Framework Programmes in a } \\
\text { System in Transition }\end{array}$ \\
\hline MT-DP. 2004/2 & $\begin{array}{l}\text { Max GILLMAN-Michal } \\
\text { KEJAK }\end{array}$ & $\begin{array}{l}\text { Inflation and Balanced-Path Growth with Alternative } \\
\text { Payment Mechanisms }\end{array}$ \\
\hline MT-DP. 2004/3 & $\begin{array}{l}\text { L. AMBRUS-LAKATOS- } \\
\text { B. VILÁGI-J. VINCZE }\end{array}$ & $\begin{array}{l}\text { Deviations from interest rate parity in small open } \\
\text { economies: a quantitative-theoretical investigation }\end{array}$ \\
\hline MT-DP. 2004/4 & $\begin{array}{l}\text { HALPERN László és } \\
\text { szerzőtársai }\end{array}$ & A minimálbér költségvetési hatásai \\
\hline MT-DP. 2004/5 & FALUVÉGI Albert & $\begin{array}{l}\text { A társadalmi-gazdasági jellemzők területi alakulása } \\
\text { és várható hatásai az átmenet időszakában }\end{array}$ \\
\hline MT-DP. 2004/6 & Mária CSANÁDI & $\begin{array}{l}\text { Budget constraints in party-states nested in power rela- } \\
\text { tions: the key to different paths of transformation }\end{array}$ \\
\hline MT-DP. 2004/7 & Mária CSANÁDI & $\begin{array}{l}\text { A comparative model of party-states: the structural } \\
\text { reasons behind similarities and differences in self- } \\
\text { reproduction, reforms and transformation }\end{array}$ \\
\hline MT-DP. 2004/8 & KARSAI Judit & $\begin{array}{l}\text { Helyettesítheti-e az állam a magántőke-befektetőket? } \\
\text { Az állam szerepe a magántőke-piacon }\end{array}$ \\
\hline MT-DP. 2004/9 & Judit KARSAI & $\begin{array}{l}\text { Can the state replace private capital investors? Public } \\
\text { financing of venture capital in Hungary }\end{array}$ \\
\hline MT-DP. 2004/10 & Mária CSANÁDI & Do party-states transform by learning? \\
\hline MT-DP. 2004/11 & $\begin{array}{l}\text { István CZAJLIK - János } \\
\text { VINCZE }\end{array}$ & $\begin{array}{l}\text { Corporate law and corporate governance. The } \\
\text { Hungarian experience }\end{array}$ \\
\hline MT-DP. 2004/12 & L. HALPERN et al & $\begin{array}{l}\text { Firms' Price Markups and Returns to Scale in } \\
\text { Imperfect Markets: Bulgaria and Hungary }\end{array}$ \\
\hline MT-DP. 2004/13 & Norbert MAIER & Explaining Corruption: A Common Agency Approach \\
\hline MT-DP. 2004/14 & Gergely CSORBA & $\begin{array}{l}\text { Screening Contracts in the Presence of Positive Net- } \\
\text { work Effects }\end{array}$ \\
\hline MT-DP. 2004/15 & K. BOGNÁR - L. SMITH & We Can't Argue Forever \\
\hline MT-DP. 2004/16 & $\begin{array}{l}\text { JUHÁSZ A. - SERES A. } \\
\text { - STAUDER M. }\end{array}$ & A kereskedelmi koncentráció módszertana \\
\hline MT-DP. 2004/17 & Júlia LENDVAI & Inflation Inertia and Monetary Policy Shocks \\
\hline MT-DP. 2004/18 & $\begin{array}{l}\text { A. FREDERIKSEN - } \\
\text { E. TAKÁTS }\end{array}$ & $\begin{array}{l}\text { Optimal incentive mix of performance pay and efficiency } \\
\text { wage }\end{array}$ \\
\hline MT-DP. 2004/19 & Péter KONDOR & $\begin{array}{l}\text { The more we know, the less we agree: public } \\
\text { announcement and higher-order expectations }\end{array}$ \\
\hline MT-DP. 2004/20 & $\begin{array}{l}\text { B. BARANYI - I. } \\
\text { BALCSÓK }\end{array}$ & $\begin{array}{l}\text { Határ menti együttmüködés és a foglalkoztatás - } \\
\text { kelet-magyarországi helyzetkép }\end{array}$ \\
\hline MT-DP. 2004/21 & L.Á. KÓCZY - L. LAUWERS & The minimal dominant set is a non-empty core-extension \\
\hline MT-DP. 2004/22 & Miklós KOREN & $\begin{array}{l}\text { The law of two prices: trade costs and relative price } \\
\text { variability }\end{array}$ \\
\hline
\end{tabular}

Papers can be downloaded from the homepage of the Institute of Economics: http://econ.core.hu 


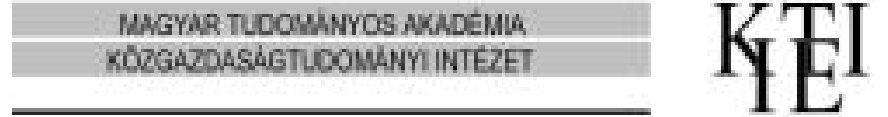

MÜHELYTANULMÁNYOK
DISCUSSION PAPERS

MT-DP. 2004/23

\section{Network MARKets ANd Consumer CoORdination}

BY ATTILA AMBRUS AND RossElla ARgENZIANO

\section{Abstract}

This paper analyzes pricing decisions and competition in network markets, assuming that groups of consumers can coordinate their choices when it is in their interest, if coordination does not require communication. It is shown that multiple asymmetric networks can coexist in equilibrium. A monopolist might operate multiple ex ante identical networks to price differentiate. In Bertrand competition different firms might target high reservation value consumers on different sides of the market. Firms can obtain positive profits in price competition. Product differentiation in equilibrium is endogenized by consumers' network choices. Enough heterogeneity in reservation values is necessary for existence of these asymmetric equilibria.

JEL classification numbers: D43, D62, L11, L14

Keywords: two-sided markets, network externalities, platform competition, coordination 
MT-DP. 2004/23

Ambrus ATtila - Rossella ARgENZIANO

HÁLÓZATI PIACOK ÉS A FOGYASZTÓK KOORDINÁCIÓJA

\section{Összefoglalás}

A jelen tanulmány célja árazási döntések és az árverseny hatásainak vizsgálata hálózati piacokon. Az analizis feltételezi, hogy fogyasztók csoportjai koordinálni tudják a döntéseiket akkor, ha ez a koordináció nem igényel kommunikációt. Megmutatjuk, hogy egyensúlyban több aszimmetrikus hálózat müködhet egymás mellett. Egy monopol helyzetben levö cég több ex ante azonos hálózatot müködtethet árdiszkriminációs célzattal. Bertrand típusú verseny esetén különbözö cégek különbözö piacok magas rezervációs árú fogyasztóira specializálódhatnak. Az árverseny nem feltétlenül vezet zéró profithoz. A hálózatok minősége ezekben az egyensúlyokban endogén módon hatarozódik meg, a fogyasztók döntései alapján. A fenti aszimmetrikus egyensúlyok létezéséhez szükséges az, hogy a fogyasztók rezervációs értékei megfelelöen heterogének legyenek. 


\section{Introduction}

A market has network externalities if consumers' utility from purchasing a product depends on which other consumers buy the same product. A highlighted special case of this is two-sided markets with network externalities. In these markets consumers are divided into two distinct subgroups. A consumer's utility on one side increases in the total number of consumers on the other side of the market who buy the same product (and possibly decreases in the number of consumers on the same side of the market). This applies to various situations in which two groups of agents need a common platform to interact and one or more firms own platforms and sell access to them. The higher the number of agents on one side who join a platform, the higher the utility of an agent on the other side of the platform because she has a higher number of potential partners with whom to trade or interact. One example of this is the market for on-line matchmaking services where the two sides are women and men. In other cases the two sides are buyers and sellers and the platforms are auction websites, directory services, classified advertisers and credit card networks (the sellers are merchants who accept the credit card and the buyers are credit card holders).

This paper investigates the decisions of firms regarding how many networks to operate and how to price them, and the network choices of consumers in two-sided markets with network externalities. We consider an extensive form game in which in the first stage firms establish networks, in the second stage they announce registration fees for these networks, and in the third stage consumers simultaneously choose networks or decide to stay out of the market.

The first contribution of this paper is methodological. Equilibrium analysis on network markets is an involved task. The coordination problems that arise among consumers result in a severe multiplicity of equilibria both in games in which there is a monopolist network provider and in games in which there are multiple providers. Consumers can have various selffulfilling expectations regarding which networks other consumers join and whether they join any network at all. To address the issue of multiplicity of equilibria we use the concept of coalitional rationalizability, proposed by Ambrus ([02],[03]) to select equilibria and therefore derive qualitative predictions. Informally, this method corresponds to assuming that consumers can coordinate their network choices as long as it is in their joint interest and this coordination does not require explicit communication. 
The second contribution of the paper is that this methodology allows us to analyze pricing games in which consumers in the market are heterogeneous. This makes it possible to ask a new set of questions. These include whether price discrimination among different type of consumers is possible without product differentiation, whether there can be multiple active networks operated by competing firms, attracting different types of consumers, and whether it can be in the interest of a monopolistic network provider to operate multiple networks, aimed at different sets of consumers.

Coordination failures and the resulting inefficiencies are relevant phenomena in network markets, since typically there are many anonymous consumers who cannot communicate with each other. Nevertheless, in some cases it is reasonable to expect consumers to be able to coordinate on a particular network. The simplest example is if there are two networks and one is cheaper on both sides of the market. Choosing this network is then a natural focal point on which consumers can coordinate. The central assumption of our paper is that consumers can coordinate their decisions to their advantage if their interests coincide and if coordination can be achieved without communication, as in the above case. In contrast, if there is no unique candidate network that consumers would agree to join, we do not assume successful coordination even if it is in the common interest of consumers. Our motivation for this is that if there are lot of small consumers on the market then it is practically impossible for them to get together and make explicit agreements on network choices.

Coalitional rationalizability allows us to incorporate the above assumption into the analysis. This noncooperative solution concept assumes that players can coordinate to restrict their play to a subset of the original strategy set if it is in the interest of every participant to do so. This defines a set of implicit agreements, which puts restrictions on beliefs that players can have at different stages of the game. These agreements are based on public information, the description of the game, and therefore do not require explicit communication. Furthermore, they are self-fulfilling in the sense that if participants expect each other to choose networks according to an agreement, then it is in their best interest to act according to the agreement. In the games that we analyze there can be groups of consumers who can coordinate their network choices this way after certain price announcements.

We investigate the subgame perfect equilibria of the above market games that are compatible with the additional assumption of coalitional rationalizability. We call these equilibria coalition perfect. 
We analyze participation rates of consumers, prices charged by the firms, network sizes and firms' profits in coalition perfect equilibria. The analysis is carried out for the cases of both one and two firms operating on the market. In the former case we distinguish between the case that the firm can operate only one network and the case in which it can decide to operate multiple networks.

We show that if consumers are homogeneous on the same side of the market then a monopolist network provider only establishes one network in coalition perfect equilibrium. On the other hand, if there is enough heterogeneity among consumers, a monopolist might want to establish two networks, which in equilibrium are joined by different type of consumers. The intuition is that, if there are high reservation value consumers on both sides of the market, then the monopolist wants to extract surplus from both of these groups. However, if there are relatively few of these consumers and the monopolist operates only one network, then he can charge a high price on at most one side. In order to charge a high price on one side, there have to be enough consumers on the other side of the network, which is only possible if the price charged on that side is low. On the other hand, if the monopolist establishes two networks such that one of them is cheap on one side of the market and the other network is cheap on the other side, then all consumers are willing to join some network and consumers with high reservation values are willing to join the network which is more expensive for them. The way price discrimination is achieved in these equilibria is through endogenous product differentiation. Networks are physically the same, but if one side of a network attracts a lot of consumers, then the other side of the network becomes more valuable for consumers.

In the case of two network providers competing for consumers we show that homogeneity of consumers on the same side of the market ensures that both firms' profits are zero in coalition perfect equilibrium, reestablishing the classic Bertrand result. This holds despite the fact that equilibrium prices do not have to be equal to the marginal cost (consumers on one side of the market can be subsidized). Homogeneity of the consumers also implies that there cannot be multiple asymmetric networks in coalition perfect equilibrium. On the other hand, we show that if consumers are heterogeneous, then there can be equilibria in which there are two networks that attract different type of consumers and in which firms earn positive profits. The intuition is that although firms can steal each others' consumers by undercutting their rival's prices on both sides of the market, this move is not 
necessarily profitable. In particular, undercutting might be unprofitable if it increases the number of consumers to be subsidized more than the number of consumers who pay a positive price.

In both the monopoly and the duopoly case the coalition perfect equilibria with two asymmetric networks have the feature that one network is larger and cheaper on one side of the market, while the other one is larger and cheaper on the other side. One example of this configuration is when a town has both a freely and universally distributed newspaper with classified ads and one that is not freely distributed. The first newspaper is cheaper and larger on the buyers' side. In order to compete with the freely distributed newspaper, typically the other newspaper has to have more ads posted on it, and therefore can only charge a smaller fee for posting ads. Therefore this newspaper is typically cheaper and larger on the sellers' side. Another example is on-line job search, where the two main platforms are Careerbuilder.com and Monster.com. Monster has a database of 25 million resumes versus Careerbuilder's 9 million, therefore larger on the job seekers' side. On the other hand, Careerbuilder has $45.2 \%$ of the job postings of the on-line job search market in the US, while Monster has only $37.5 \% .^{1}$ Therefore Careerbuilder is larger on this side. And to post a job on Careerbuilder, a firm pays $\$ 269$, while to post a job on Monster a firm pays $\$ 335 .^{2}$

\section{Related literature}

Recently a number of papers investigated the issue of optimal pricing and price competition in markets with two-sided network externalities. For a more extensive literature review, see for example Armstrong (2002).

Rochet and Tirole (2003) and Armstrong (2002) study monopolistic pricing and price competition between two firms on markets where the firms are platforms that try to attract two groups of agents. The models in these papers abstract away from coordination problems among consumers. They

\footnotetext{
${ }^{1} 2004$ February figures. The information about the size of the two databases is taken form www.careerbuilder.com and www.monster.com. The information about the number of job postings is obtained from Corzen.

${ }^{2}$ The base cost of posting a resume is zero on both sites, but job seekers pay extra fees for preferential treatment of their resumes (for example if they want them to come up at the top of search result lists obtained by firms). We do not have information on how many job seekers pay these extra fees, therefore we cannot make a correct price comparison on this side of the market.
} 
assume differentiable demand functions for the networks, implicitly assuming differentiated networks (that consumers have heterogeneous inherent preferences between networks). Also, they focus on a particular symmetric equilibrium. Moreover, Rochet and Tirole emphasize the case in which the networks' primary pricing instrument are transaction fees.

Jullien (2001) constructs a duopoly model that allows for more than two subgroups of consumers and for both inter-groups and intra-group network externalities. The setup of this paper differs from ours in that the intrinsic value of the good sold by each firm is assumed to be high compared to the network effect and also that one of the firms is highlighted in the sense that consumers always coordinate on the equilibrium which is the most favorable for this firm.

Ellison, Fudenberg and Mobius (2002) study competition between two auction sites. In their model, like in ours, multiple asymmetric platforms can coexist in equilibrium, despite no product differentiation. In addition to this, they assume heterogeneous agents on both sides of the market. On the other hand, in their model consumers choose platforms ex ante, while in our paper they do it after learning about their types. Furthermore, the reason that multiple active networks can coexist in equilibrium is completely different in their model. They consider a finite number of buyers and sellers, therefore one of them switching from one platform to another adversely affects the market price on the latter platform. ${ }^{3}$ In our model there is a continuum of consumers on both sides of the market, therefore this market-impact effect is absent.

The model in Damiano and Li (2003a and 2003b) is similar to ours in that consumers on a two-sided market are heterogeneous and that registration fees serve the role to separate different types of consumers. The main difference between our setup and theirs is that in the latter there is no network externality. Consumers care about the average quality of consumers on the other side of the network and not their number. On the other hand, in our model consumers are symmetric with respect to the external effect they generate on consumers on the other side.

The most similar model to ours is presented by Caillaud and Jullien (2001 and 2003). They analyze markets where firms are intermediaries offering matchmaking services to two groups of agents. The above papers assume

\footnotetext{
${ }^{3}$ See Ellison and Fudenberg (2003) for a detailed analysis of this point.
} 
that consumers on each side are homogeneous and their utility is linear in the number of consumers on the other side of the network. ${ }^{4}$ The assumption of homogeneity implies that these papers do not address most of the issues we investigate in this paper. Also, Caillaud and Jullien select among equilibria by imposing monotonicity on the demand function of consumers and by assuming full market coverage in equilibrium. As opposed to making an assumption on the aggregate demand function our paper imposes restrictions directly on the expectations of individual players.

In our model different types of consumers might select to join different networks. In this aspect, our analysis is connected to the literature on price discrimination (for an overview see Varian (1987)) multiproduct pricing (see Baumol et al. (1982)) and the theory of screening (for an overview see Salanie (1997)).

\section{The Model}

We consider a standard model of price competition in two-sided markets with network externalities. It is a sequential move game in which first firms announce prices, then consumers observe the announcements, and finally consumers choose which network to join, if any. We examine the cases of one or two firms operating in the market. The added features of our model are the following. First, in the monopoly case we allow the firm to choose the number of networks to be established. Second, consumers are not assumed to be homogeneous in that how much they value the network good. Third, we do not make any restriction on the utility functions of consumers besides quasilinearity in money.

Formally, the set of players in the model is $\left(F, C^{1}, C^{2}\right)$, where $F$ denotes the firms, while $C^{1}$ and $C^{2}$ the consumers of the corresponding sides. We assume there is a continuum of consumers on both sides of the market, indexed by the interval $[0,1]$. Let $C_{i}^{k}$ denote consumer $i$ on side $k$. As far as firms are concerned, we restrict attention to the cases $F=\{A\}$ (only one firm, $A$ is present) and $F=\{A, B\}$ (two firms, $A$ and $B$ are present).

We consider a three-stage game with observable actions (after every stage all players observe all action choices made in that stage).

\footnotetext{
${ }^{4}$ For a comparison between our results in this context and the ones of Caillaud and Jullien (2003), see Subsection 7.1.
} 
In the first stage the firms simultaneously choose how many networks to establish. We will restrict attention to cases when the maximum number of networks a firm can operate is either one (in which case decisions at this stage are trivial) or two. Let $n_{k}$ denote the first stage action of firm $k$. Furthermore, let $\left(\tau_{k}^{m}\right)_{m=1, \ldots, n_{k}}$ denote the networks that firm $k$ establishes.

In the second stage the firms simultaneously set prices (registration fees) on the established networks. Firms can charge different registration fees on different networks or on different sides of the same network. Furthermore, they can charge negative prices on either side of the networks (subsidizing consumers on that side). Let $p_{k, n}^{j}$ denote the price that firm $k$ sets on side $j$ of $\tau_{k}^{n}$. If every firm can only have one network, then we use the simpler notation $p_{k}^{j}$.

In the third stage the consumers simultaneously choose which network to join, if any. We assume that a consumer can join at most one network (exclusivity of networks). ${ }^{5}$

Firms maximize profits. Let $\pi_{k}$ denote the profit of firm $k$. We assume that firms are symmetric and that the cost of operating a network is zero, independently of the number of consumers joining the network. ${ }^{6}$ Then the payoff of the firm is the sum of the revenues collected from the firm's networks, where the revenue collected from a network is sum of the revenue collected on side 1 and the revenue collected on side 2 . Let $N_{k, n}^{j}$ denote the number of consumers on side $j$ who join network $\tau_{k}^{n} \cdot{ }^{7}$ If the maximum number of networks k can operate is 1 then we use the simpler notation $N_{k}^{j}$. Then $\pi_{k}=\sum_{n=1, \ldots, n_{k}} \sum_{j=1,2} p_{k, n}^{j} N_{k, n}^{j}$.

Consumer $i$ on side $j$ maximizes the individual-specific utility function $U_{i}^{j}$. Let $U_{i}^{j}=0$ if she does not join any network. Let $U_{i}^{j}=g_{i}^{j}\left(N_{k, n}^{-j}\right)-p_{c_{i}^{j}}^{j}$ if she joins network $\tau_{k}^{n}$. Assume $g_{i}^{j}(0)=0$ and that $g_{i}^{j}$ is increasing for every consumer $C_{i}^{j}{ }^{8}$ A consumer's utility if joining a network is quasilinear in

\footnotetext{
${ }^{5}$ See Section 8 for a discussion on relaxing this assumption.

${ }^{6}$ See Section 8 for a discussion on how the results affected by assuming a positive marginal cost.

${ }^{7}$ More precisely, the Lebesgue measure of consumers on that side joining the network. We leave payoffs undefined for cases where the latter set is not measurable.

${ }^{8} \mathrm{We}$ assume that network participation is a pure network good for analytical convenience. Most results of the paper could be generalized to the case of $g_{i}^{j}(0) \geq 0$.
} 
money and increases in the number of people joining the network from the other side of the market. ${ }^{9}$ Implicit in the construction is that consumers do not have any inherent preference for joining one network or another, they only care about the number of people joining the networks and the price they have to pay.

Let $u_{i}^{j}=g_{i}^{j}(1)$. We call $u_{i}^{j}$ the reservation value of consumer $i$ on side $j$.

If $g_{i}^{j}=g_{i^{\prime}}^{j} \forall i, i^{\prime} \in[0,1]$ and $j \in\{1,2\}$, then we say consumers are homogeneous. A special case of the above specification, that received highlighted attention in the existing literature, is when for every $j=1,2$ and $i \in[0,1]$ it holds that $g_{i}^{j}\left(N_{k, n}^{-j}\right)=u^{j} N_{k, n}^{-j}$ (consumers on the same side have the same linear utility function).

\section{Coalitional rationalizability and coalition per- fect equilibrium}

The central assumption of our paper is that at every stage of the game players can coordinate their actions whenever it is in their joint interest and it does not require communication. The formal concept we use is coalitional rationalizability. It is a solution concept that builds on the idea that whenever it is in the mutual interest of some group of players (a coalition) to restrict their play to a certain subset of the strategy space (to implicitly agree upon not playing some strategies) then these players indeed expect each other to make this restriction. These restrictions are called supported. The set of coalitionally rationalizable strategies are the outcomes that are consistent with common certainty of the assumption that play is consistent with every supported restriction by every coalition. For the formal construction see Ambrus [02].

In the forthcoming analysis we restrict attention to pure strategy subgame perfect equilibria in which players play coalitionally rationalizable strategies in every subgame. We call these outcomes coalition perfect equilibria. ${ }^{10}$

\footnotetext{
${ }^{9}$ The above specification makes the simplifying assumption that a consumer's utility is independent of how many consumers join the network on her side, implicitly assuming that interacting with consumers on the other side is a nonrival activity. Section 8 discusses implications of partially relaxing this assumption.

${ }^{10} \mathrm{It}$ is possible to show that in our context the requirement that players play coalitionally rationalizable strategies in every subgame is outcome equivalent to the concept of extensive
} 
Definition: a strategy profile is a coalition perfect equilibrium if it is a subgame perfect Nash equilibrium and in every subgame every player plays some coalitionally rationalizable strategy.

Intuitively, coalition perfect equilibrium requires that supported restrictions can be made not only at the beginning of the game, but after any publicly observed history, and that players at any stage of the game foresee restrictions that are made at later stages. In the games we consider coalitional rationalizability puts restrictions in certain subgames on consumers' beliefs concerning other consumers' choices. To provide some intuition on this, we proceed with an informal definition of supported restriction in consumer subgames, and three examples of such restrictions.

Consider a third stage (consumer) subgame. Assume that players are certain that play is in some subset $S^{\prime}$ of the set of strategies. Then a coalition of consumers supports restricting play to a subset $S^{\prime \prime}$ of $S^{\prime}$ if for any player in the coalition the following condition holds. No matter what beliefs she has concerning the choices of consumers outside the coalition, her expected payoff is always strictly higher if the restriction is made (if every player in the coalition plays inside $S^{\prime \prime}$ ) than if the restriction is not made and she plays some strategy outside $S^{\prime \prime}$.

For the first example suppose $F=\{A, B\}$ and that for every $j=1,2$ and $i \in[0,1]$ it holds that $g_{i}^{j}\left(N^{-j}\right)=u N^{-j}$ for some $u>0$. Consider the consumer subgame that follows price announcements $p_{k}^{j}=0 \forall j=1,2$ and $k=A, B$. Then the restriction to join either $A$ 's network or $B$ 's network (or agreeing upon not to stay out of the market) is a supported restriction for the coalition of all consumers, because if the restriction is made, then any possible conjecture that is compatible with it is such that a best response to it yields expected payoff of at least $u / 2$ (the conjecture should allocate an expected size of at least $1 / 2$ to one of the two networks), while staying out of the market yields zero payoff. Because prices charged by the two networks are the same, no more strategies are eliminated by coalitional rationalizability in this subgame. Both joining $A$ 's network and joining $B$ 's network are coalitionally rationalizable for every consumer and therefore this subgame has three coalitionally rationalizable Nash equilibria. Either every

form coalitional rationalizability (see Ambrus[03]). 
consumer joins $A$ or every consumer joins $B$, or one half of the consumers on both sides joins each network.

Next, consider the subgame in the same game that follows price announcements $p_{A}^{j}=0$ and $p_{B}^{j}=u / 4 \forall j=1,2$. In this subgame $A$ is a supported restriction for the coalition of all players, since it yields payoff $u$ to all consumers, while joining $B$ 's network can yield a payoff of at most $3 u / 4$ and staying out yields 0 . Coalitional rationalizability pins down a unique strategy profile in this subgame.

If consumers are heterogeneous then the set of coalitionally rationalizable outcomes in a subgame might only be reached after multiple rounds of agreements. Suppose $F=\{A, B\}$, consumers have linear utility functions and $u_{i}^{1}=1 i \in[0,1 / 2], u_{i}^{1}=1 / 2 i \in(1 / 2,1]$ and $u_{i}^{2}=1 i \in[0,1]$. In words, consumers on side 2 are homogeneous, while half of the consumers on side 1 have relatively low reservation values. Consider the subgame following price announcements $p_{A}^{1}=.4, p_{A}^{2}=.8$ and $p_{B}^{1}=.8, p_{B}^{2}=.4$. Initially, there is no supported restriction for the coalition of all consumers. Consumers would prefer to coordinate their network choices, but coordinating on $A$ is better for side 1 consumers, while coordinating on $B$ is better for side 2 consumers. However, note that joining $B$ is not rationalizable for any consumer $C_{i}^{1}$ for $i \in(1 / 2,1]$ and therefore not joining $B$ is a supported restriction for these consumers. Once it is established that players $C_{i}^{1}$ for $i \in(1 / 2,1]$ only consider strategies $\emptyset$ or $A$, it is a supported restriction for the coalition of all consumers to join $A$. Therefore coalitional rationalizability pins down a unique outcome in this subgame as well.

The sequential structure of the game implies that there are no supported restrictions in the game that involve both firms and consumers. By the time consumers move, firms already made their choices and those choices were observed by the consumers. And since consumers cannot commit themselves to make choices that are not in their interest, there are no credible implicit agreements between firms and consumers. Showing this formally is straightforward and therefore omitted from here. It is less straightforward to establish that there are no supported restrictions between two firms, and we could not establish a result like that for the general specification. However, we did not find any example in which there is a supported restriction by firms. Firms in our model are competitors and they only move once, therefore their possibilities to make credible and mutually advantageous restrictions are very limited. 
We note that the solution concept we use is not equivalent to coalitionproof Nash equilibrium (Bernheim, Peleg and Whinston (1987)) or Pareto efficiency in the consumer subgames. In consumer subgames in which there is a unique Pareto efficient outcome coalition perfect equilibrium implies that the efficient outcome is played. But in subgames with multiple Pareto efficient outcomes it is consistent with coalition perfect equilibrium that a Pareto inefficient outcome is played. Also if consumers are heterogeneous, then not every Pareto efficient outcome is consistent with coalition perfect equilibrium. In general, none of the results of the paper for heterogeneous consumers would hold if instead of coalitional rationalizability we assumed Pareto efficiency in consumer subgames. ${ }^{11}$ As far as coalition-proof Nash equilibrium is concerned, it can be shown that in our model it is a stronger concept than coalitionally rationalizable Nash equilibrium, implying that it assumes a more effective form of coordination than what we impose. ${ }^{12}$ It can be established that both the range of network choices and equilibrium prices can be larger in coalition perfect equilibrium than in coalition-proof Nash equilibrium. ${ }^{13}$ The above implies that those results of this paper that establish properties of all coalition perfect equilibria are valid for (the strictly smaller set of) perfect coalition-proof equilibria too.

We do not investigate the issue of existence of pure strategy coalition perfect equilibrium here. It is possible to show that under some technical conditions every game with one firm has a pure strategy coalition perfect equilibrium, while every game with two firms has a coalition perfect equilibrium in which consumers play pure strategies and only firms use mixed strategies. ${ }^{14}$ We restrict attention to pure strategies to keep the analysis tractable. In all examples we provide in the paper there exists a pure strategy coalition perfect equilibrium.

\section{Monopolist with one network}

\footnotetext{
${ }^{11}$ One intuition for this is that if in every equilibrium of a consumer subgame there are some consumers who do not join any network, then the requirement of Pareto efficiency is very weak (consumers who stay out get utility zero, no matter how many other consumers stay out or how many consumers join one network versus the other).

${ }^{12}$ In particular, it assumes successful coordination even when there are multiple outcomes in a subgame that cannot be ruled out by the logic of coalitional agreements. In our view in these cases coordination can only be achieved through explicit agreements, which is not possible in the settings we consider.

${ }^{13}$ See the earlier version of our paper for an example.

${ }^{14}$ The conditions are that utility functions are differentiable and there is a uniform bound on their derivatives.
} 
In this subsection we assume $F=\{A\}$ and that firm $A$ can only establish one network.

In a market without network externalities, subgame perfection, which is implicitly assumed when the demand function of consumers is derived, guarantees that a monopolist can achieve the maximum profit compatible with Nash equilibrium. ${ }^{15}$ In markets with network externalities the above result does not hold. Typically there are many different equilibria of the pricing game with one network provider. The consumers face a coordination problem when deciding on whether to join a network or not, which results in a wide range of subgame perfect equilibrium prices, consumer participation measures and profit levels.

In sharp contrast, Theorem 1 below establishes that in every coalition perfect equilibrium the monopolist gets the maximum profit compatible with Nash equilibrium. The intuition is the following. In any Nash equilibrium consumers who join the network get nonnegative utility. Then coalitional rationalizability guarantees that all these consumers join the network if the price is smaller than the previous equilibrium price. But then the firm is guaranteed to get a profit that is arbitrarily close to the above equilibrium profit by charging slightly smaller prices (note that if the equilibrium price on one side is negative, then all consumers on that side join the network in equilibrium, so a price decrease cannot result in having to subsidize more consumers).

The proofs of all theorems that are stated in the main section of the paper are in the Appendix.

Theorem $1 \pi_{A}$ is uniquely determined in coalition perfect equilibrium and it is equal to the maximum possible profit of $A$ in Nash equilibrium.

If consumers are homogeneous and the reservation values of consumers are $u^{1}$ on side 1 and $u^{2}$ on side 2 , then Theorem 1 implies that in any coalition perfect equilibrium that $p_{A}^{k}=u^{k}$ and $N_{A}^{k}=1 \forall k=1,2$. The assumption that consumers can implicitly coordinate their choices in this

\footnotetext{
${ }^{15}$ To give a simple example, if all consumer have the same reservation value $u>0$ for some indivisible good and the firm charges a price strictly below $u$, then subgame perfection implies that all consumers buy the good. Then in any subgame perfect Nash equilibrium the firm gets a profit of $u$ times the number of consumers.
} 
case ultimately hurts them because the firm can extract all the potential consumer surplus on the market.

A corollary of the previous observation is that if consumers are homogeneous, then it is never in the interest of the firm to establish more than one network. By providing one network the firm can extract the maximum possible gross consumer surplus on this market. If there are two active networks then gross consumer surplus is smaller than in the above case, and since no consumer can get negative utility in any Nash equilibrium, the profit of the firm is strictly smaller than in the one network case.

\section{Monopolist who can operate multiple networks}

This section investigates a monopolist network provider's decision on how many networks to operate and how to price them. Since the analysis of the model with more than two networks and heterogeneous consumers is involved, we restrict attention to the case when the monopolist can operate at most two networks.

First we show in a simple setting that it can indeed be better for the monopolist to operate two networks, despite the fact that it would be socially optimal to have all consumers on the same network. The example also demonstrates that in network markets the monopolist can effectively price discriminate among consumers through registration fees, even without product differentiation. We compare social welfare in the case the monopolist can operate only one network versus if it is allowed to operate multiple networks. For general distribution of types we provide a necessary condition for two networks being established in equilibrium.

We note that the results of this section carry over to the case when consumers can join multiple networks at the same time. ${ }^{16}$ Furthermore, the latter framework is formally equivalent to one in which the monopolist operates only one network but can sell restricted access to the network (can control which transactions can occur on the network). Therefore in that setting if there is enough heterogeneity among consumers then the monopolist might want to sell both limited access at a lower price, and full access at a higher price, on both sides of the network.

\footnotetext{
${ }^{16}$ See Subsection 8.2 for a discussion.
} 


\subsection{Two types of consumers on each side}

Here we restrict attention to a context in which the two sides of the market are symmetric, there are only two types of consumers on each side, and consumers have linear utility functions.

Assume that $g_{i}^{j}(N)=u_{i}^{j} \cdot N \forall j=1,2$ and $i \in[0,1]$. Also assume that for every $u_{i}^{1}=u_{i}^{2}=h$ for $i \in[0, a]$ and $u_{i}^{1}=u_{i}^{2}=l$ for $i \in(a, 1]$, where $l<h$ and $a \in[0,1]$.

In each side a fraction $a$ of the consumers have a reservation value $h$, which is higher than $l$, the reservation value of the rest of the consumers. We refer to consumers with reservation value $h$ as high types, and consumers with reservation value $l$ as low types ${ }^{17}$.

It is possible to show that for all parameter values $a, l$ and $h$ there exists a coalition perfect equilibrium, no matter what is the maximum number of networks that $A$ can establish. ${ }^{18}$

As a first step we characterize the set of coalition perfect equilibria when the firm can only establish one network. The coalition perfect equilibrium is almost always unique, but depends on the values of parameters $a, h$ and $l$. If $l$ is relatively low and $a$ is high, then the monopolist targets only the high type consumers and charges a high price on both sides. If $l$ is relatively high and $a$ is small, then the monopolist targets all consumers and charges a low price on both sides. In cases in between the monopolist might target all consumers on one side and only the high types on the other side, by charging a low and a high price. These results are both intuitive and in accordance with classic results from the literature on multi product pricing with heterogeneous consumers.

Define the following cutoff points:

$$
\begin{aligned}
t_{1} & \equiv 2 a-1 \\
t_{2} & \equiv \frac{a}{2-a}
\end{aligned}
$$

\footnotetext{
${ }^{17}$ Note that high and low type only refers to the reservation value of consumers and not to their quality in terms of how desirable a consumer's presence is on the network for consumers on the other side. In our model all consumers are ex ante identical in terms of this external effect.

${ }^{18}$ The previous version of the paper establishes a more general result.
} 
Notice that if $a \geq \frac{1}{2}$ then $0 \leq t_{1} \leq t_{2} \leq \frac{1}{2}$, while if $a \leq \frac{1}{2}$ then $t_{1} \leq 0 \leq$ $t_{2} \leq \frac{1}{2}$. Also, notice that both $t_{1}$ and $t_{2}$ are strictly increasing in $a$.

Theorem 2 For every coalition perfect equilibrium the following hold:

1. If $\frac{l}{h}<\max \left\{0, t_{1}\right\}$, then only the high types on both sides join the network and $p_{A}^{1}=p_{A}^{2}=$ ah

2. If $\frac{l}{h} \in\left(\max \left\{0, t_{1}\right\}, t_{2}\right)$ then there is $j \in\{1,2\}$ such that on side $j$ all consumers join the network and $p_{A}^{j}=a l$ and on the other side only high types join the network and $p_{A}^{-j}=h$.

3. If $\frac{l}{h} \in\left(t_{2}, 1\right)$ then all consumers on both sides join the network and $p_{A}^{1}=p_{A}^{2}=l$.

Finally, if $\frac{l}{h}=t_{1}$ there are coalition perfect equilibria of both type 1 and type 2 above. Similarly if $\frac{l}{h}=t_{2}$ then there are coalition perfect equilibria of both type 2 and type 3 above.

Note that if $a<1 / 2$, then there is no coalition perfect equilibrium in which the monopolist charges a high price on both sides of the market, targeting only high types. Charging a high price on one side of the market has to be accompanied by charging a low price on the other side. The reason is that there have to be enough consumers on the other side on the network for high types on the first side to be willing to pay the high price. The monopolist therefore cannot extract a high level of consumer surplus from both sides of the market simultaneously.

Assume now that the maximum number of networks $A$ can establish is 2. The next theorem shows that for a range of parameter values in every coalition perfect equilibrium the monopolist chooses to operate two networks and high and low type consumers on the same side of the market choose different networks.

Define the following cutoff points:

$$
\begin{aligned}
& z_{1} \equiv 4 a-1 \\
& z_{2} \equiv \frac{a(1-2 a)}{1-a}
\end{aligned}
$$


Notice that if $a \in\left[0,1-\frac{\sqrt{2}}{2}\right]$ then $t_{1} \leq z_{1} \leq t_{2} \leq z_{2}$. and both $z_{1}$ and $z_{2}$ are strictly increasing in $a$.

Theorem 3 If $a \in\left(0,1-\frac{\sqrt{2}}{2}\right)$ and $\frac{l}{h} \in\left(\max \left\{0, z_{1}\right\}, z_{2}\right)$ then the following hold for every coalition perfect equilibrium:

(1) $n_{A}=2$

(2) There is $n \in\{1,2\}$ such that all high types on side 1 and all low types on side 2 join $\tau_{k}^{n}$, while all low types on side 1 and all high types on side 2 join $\tau_{k}^{-n}$. The prices are $p_{A, n}^{1}=p_{A,-n}^{2}=h(1-2 a)+$ al and $p_{A, n}^{2}=p_{A,-n}^{1}=a l$.

Note that this range of parameter values cuts into the region in which a monopolist with one network would target all consumers on both sides and into the region in which it targets only high type consumers on one side and all consumers on the other.

By establishing two networks and pricing them differently the monopolist implements a form of second degree price discrimination. In particular, if the proportion of high types is sufficiently low, then the monopolist can separate the low types and the high types on each side even if reservation values are unobservable, by charging a high price on side 1 and a low price on side 2 in one network, and doing the opposite on the other network ${ }^{19}$. An appropriate choice of prices results in low type consumers choosing networks that are relatively cheap for them, while high type consumers choosing the ones that are relatively expensive for them. In equilibrium the two networks, despite being physically equivalent, end up being of different quality. In our framework the quality of a network for a consumer is determined by how many consumers join the network on the other side of the market. If the majority of consumers on each side of the market are low types, then when all low type consumers on side 1 join one network, that network becomes higher quality for side 2 consumers. Similarly when all low type consumers on side 2 join one network, that network becomes higher quality for side 1 consumers. Since in the above equilibria the low type consumers join different networks,

\footnotetext{
${ }^{19}$ Note that coalitional rationalizability implies that in order to have two active networks in equilibrium they either have to have exactly the same prices, or one network has to be relatively cheaper on one side, while the other one on the other side. Therefore there cannot be coalition perfect equilibria with two networks with one being large and expensive on both sides, while the other small and cheap on both sides.
} 
one network ends up being high quality for side 1 consumers, while the other one for side 2 consumers. High type consumers have a higher willingness to pay for quality and therefore are willing to join the networks that are more expensive for them.

The result that in equilibrium the monopolist separates consumers on the same side by offering them two products that have different prices and qualities is standard in the adverse selection literature ${ }^{20}$. What is special to this model is that the two networks are ex-ante identical and product differentiation is endogenous. The quality of a network is determined in equilibrium by the network choices of the consumers, which are driven by the prices of the networks.

The reason the monopolist might be better off by the price discrimination is that it can extract a large consumer surplus from high type consumers simultaneously on both sides of the market, something that it cannot achieve by operating only one network (see Figure 1 for an illustration).

Notice that in the above equilibrium the firm sacrifices some gross consumer surplus (it is socially efficient if all participating consumers are on the same network) in order to be able to extract a high share of the surplus from consumers with high reservation values on both sides of the market.

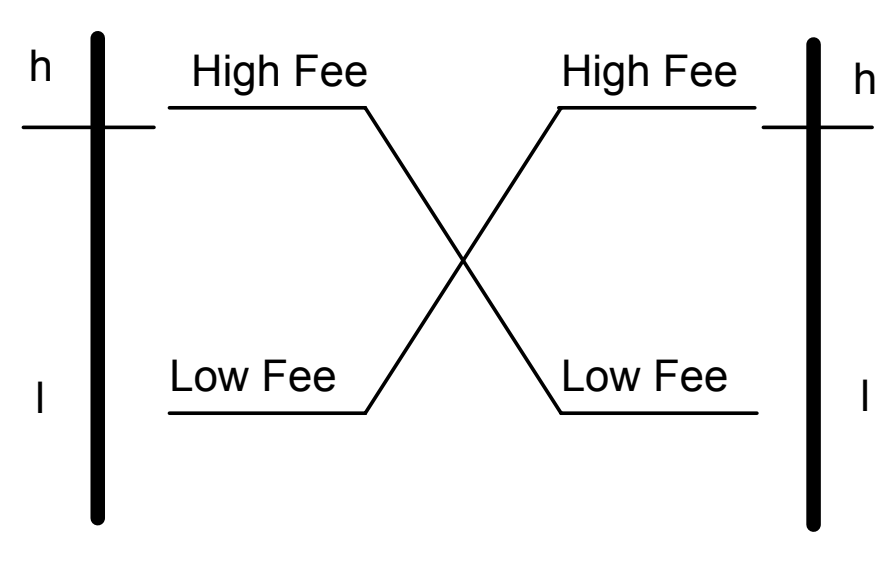

SIDE 1

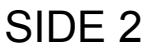

Figure 1

${ }^{20}$ See Mussa-Rosen (1978) and Maskin-Riley (1984). 
Despite this, the aggregate social welfare in the situation in which the monopolist is not allowed to operate multiple networks can be both higher or lower than in the situation in which it can only operate one. If $\frac{l}{h} \in\left(t_{2}, z_{2}\right)$ then a monopolist operating only one network charges prices $(l, l)$ and all consumers join the network. This generates a higher aggregate surplus than if the monopolist can operate two networks, because the same set of consumers participate in the market both cases, but more surplus is generated if they all join same network. As far as consumer surplus is concerned, high types are better off if the monopolist can only run one network and low types are indifferent (they get zero utility in both cases). On the other hand if $\frac{l}{h} \in\left(z_{1}, t_{2}\right)$, then being restricted to operate one network the monopolist sets a price of $h$ on one side and la on the other. Only high types join the network on the first side and all consumers on the other side. In this case high type consumers are better off if the monopolist can operate two networks and low types are again indifferent. Furthermore, it is straightforward to establish that aggregate social surplus is higher in the case of two networks. In case of two networks aggregate surplus is $2(a h(1-2 a)+a l)+2 a^{2}(h-l)$, while in case of one network it is $a h+a l+a^{2}(h-l)$. The difference of the two surpluses is $a h+a l-3 a^{2} h-a^{2} l$, which is positive given that $\frac{l}{h}<1$ and $\frac{l}{h} \geq z_{1}=4 a-1$ implies $a<\frac{1}{4}$.

Equilibrium prices and quantities have to satisfy the "incentive compatibility constraints" that a high type consumer should prefer the more expensive network, while a low type consumer should prefer the cheaper network. Furthermore, since staying out of the market is an option to every consumer, consumers have to get nonnegative utility in equilibrium - a "participation constraint". One feature of the above result, which is consistent with the literature on adverse selection, is that the incentive compatibility constraints for the high types and the participation constraints for the low types are binding in equilibrium.

\subsection{General specification}

The question of when it is in the interest for the monopolist to operate multiple networks is difficult to answer in general. ${ }^{21}$ One result in the restricted

\footnotetext{
${ }^{21}$ One complication is that as opposed to the case of two types of consumers on each side, in general the profit of a monopolist might not be uniquely determined in coalition perfect equilibrium. The previous version of the paper provides an example in which there are coalition perfect equilibia in which only one network is established, but there are also coalition perfect equilibria in which two networks are established, yielding different profit
} 
setting of the previous subsection is that the reservation values of high and low type consumers have to be sufficiently different for the monopolist wanting to establish two networks. Below we show that this can be extended to a more general setting. In particular we provide a lower bound on the ratio of the highest and lowest reservation value which is consistent with two networks being operated by the monopolist, provided that consumers' utility functions are convex (including the linear specification).

Let $F=\{A\}$ and let the maximum number of networks $A$ can establish be 2 . Assume that $g_{i}^{j}$ is weakly convex for every $j=1,2$ and $i \in[0,1]$.

Theorem 4 If $u_{i}^{j} / u_{i^{\prime}}^{j}<3+2 \sqrt{2}$ for every $j=1,2$ and $i, i^{\prime} \in[0,1]$ then in every coalition perfect equilibrium either $n_{A}=1$, or $\exists n \in\{1,2\}$ such that $N_{A, n}^{k}=0$ for some $k \in\{1,2\}$.

The central point of the proof is that the above assumptions guarantee that establishing one network and charging prices equal to the lowest reservation values is always more profitable than establishing two active networks. Recall that establishing two active networks implies sacrificing some consumer surplus, which limits the price that the monopolist can charge on the networks. Therefore it can only be profitable if there are some consumers on both sides of the market with sufficiently high reservation values relative to the rest of the consumers.

\section{Duopoly}

In this section we consider two firms operating in the market, each allowed to establish only one network. Just like in the case of one firm operating in the market, typically there are many different types of subgame perfect Nash equilibria, including one in which no consumers participate in the market. There are also equilibria in which firms get positive profits. ${ }^{22}$

levels. This is possible because coalitional rationalizability does not uniqely determine choices in every consumer subgame.

${ }^{22}$ The presence of so called "divide and conquer" strategies (introduced by Innes and Sexton[93], and then analyzed in the context of network markets by Jullien[01] and Caillaud and Jullien[01]) restricts the set of SPNE. If a firm charges a sufficiently low (negative) price compared to its rival on one side of the market, it can make its network a dominant choice for consumers on that side. Then it can charge a high price on the other side of the market and still make sure that consumers join its network on that side. Despite this there is typically a severe multiplicity of equilibria. 
We investigate whether the assumption of coalitional rationalizability reestablishes the result that firms' profits are zero in Bertrand competition for markets with network externalities. Furthermore we ask whether there exist coalition perfect equilibria in which asymmetric networks coexist in the market, with different types of consumers choosing different networks. First we address these questions in the special case that all consumers on the same side have the same reservation values, where we can characterize the set of coalition perfect equilibria. Then we investigate the case of heterogeneous consumers, where we provide an example to show that there might be coalition proof equilibria with novel features, and obtain a partial characterization result.

\subsection{Homogeneous consumers}

In this subsection we assume that consumers on the same side have the same reservation value, $u^{1}$ on side 1 and $u^{2}$ on side 2 . It can be shown that in all these games there exists coalition perfect equilibria.

Theorem 5 establishes that in this case coalition perfect equilibria of the duopoly game have similar properties to subgame perfect equilibria of duopoly pricing games with no network externalities. Namely in every coalition perfect equilibrium both firms' profits are zero, and if both of them are active then they charge the same prices and have the same size. The difference is that in this two-sided market environment prices do not have to be zero, despite the assumption that the marginal cost is zero. It is compatible with coalition perfect equilibrium that consumers on one side of the market pay a positive price for joining a network, while consumers on the other side are subsidized to join. In fact Theorem 6 below shows that if the two sides are asymmetric $\left(u^{1} \neq u^{2}\right)$, then in every coalition perfect equilibrium the side with the smaller reservation value gets strictly subsidized, and consumers on the other side pay a strictly positive price.

Theorem 5 There can be two types of coalition perfect equilibria:

1. $\exists k \in\{A, B\}$ such that $N_{k}^{j}=1 \forall j=1,2$ and $i \in[0,1], p_{k}^{1}=-p_{k}^{2}$ and $p_{k}^{j} \leq u^{j} \forall j=1,2$

2. $N_{A}^{1}=N_{A}^{2}=N_{B}^{1}=N_{B}^{2}=1 / 2, p_{A}^{1}=p_{B}^{1}=-p_{A}^{2}=-p_{B}^{2}$ and $p_{A}^{j} \leq u^{j} \forall$ $j=1,2$ 
Either all consumers join the same network, or the two networks charge the same prices and split the consumers equally. In all equilibria no consumer stays out of the market and all consumers on the same side of the market pay the same price. This market price on one side of the market is just the negative of the price on the other side. Therefore either both prices are zero, or consumers on one side pay a positive price while consumers on the other side receive an equivalent subsidy. In all equilibria both firms' profits are zero.

The intuition behind the zero profit result is that coalitional rationalizability implies that slightly undercutting the competitor's price on both sides of the market results in stealing the whole market. Then if in some profile at least one firm's profit is positive, then at least one firm could profitably deviate by slightly undercutting the other firm's prices. Furthermore, even in profiles in which firms get zero profit but active firms do not charge the same prices at least one firm could profitably deviate by undercutting.

The result of full consumer participation comes from the fact that in all the above equilibria either the market price (the price charged by the active firm(s)) is negative on one side, or the market price is zero on both sides. The first case implies that consumers on the side with the negative market price do not stay out of the market, and then the zero profit result can be used to show that there has to be full consumer participation on the other side as well. The intuition behind the result that every consumer joins some network is that if prices are zero then it is a supported restriction for the coalition of all consumers to agree upon joining some network. This is because even the most pessimistic expectation compatible with the agreement (namely that other consumers are equally dispersed between the two networks) yields a positive expected payoff, while staying out of the market gives a zero payoff.

Theorem 6 Assume $u^{j}<u^{-j}$ for $j \in\{1,2\}$. Then in every coalition perfect equilibrium $N_{k}^{1}+N_{k}^{2}>0$ for some $k \in\{A, B\}$ implies that $p_{k}^{j} \in\left[-u^{-j}, u^{j}-u^{-j}\right]$

Theorem 6 states that if consumers on one side have a higher reservation value than consumers on the other side, then in a coalition perfect equilibrium the price charged on the side which has the smaller reservation value has to be in an interval that is strictly below zero. The minimal amount of 
subsidy that consumers on this side get is the difference between the reservation values. This result is not a consequence of coalitional rationalizability, but comes from the restrictions that "divide and conquer" strategies put on any subgame perfect Nash equilibrium ${ }^{23}$. If the market price is positive on the side with the low reservation value, then it is relatively cheap to steal consumers on that side, and then a higher price can be charged on the side with the high reservation value.

The following claim concerning the context of linear utility functions is straightforward to establish using Theorems 5 and 6 .

Claim 1 Let $g_{i}^{j}\left(N^{-j}\right)=N^{-j} u^{j} \forall j=1,2$ and $i \in[0,1]$. Then the following hold:

- If $u^{1}=u^{2} \equiv u$, then two types of coalition perfect equilibria exist:

1. (monopoly equilibria with zero profits) $\exists k \in\{A, B\}$ such that all consumers join network $\tau_{k}, p_{k}^{1}=-p_{f}^{2}$ and $p_{k}^{j} \leq u \forall j=1,2$

2. (symmetric equilibria with zero profits) $N_{A}^{1}=N_{A}^{2}=N_{B}^{1}=N_{B}^{2}=1 / 2$, $p_{A}^{1}=p_{B}^{1}=-p_{A}^{2}=-p_{B}^{2}$ and $p_{A}^{j} \leq u / 2 \forall j=1,2$

- If $u^{j}<u^{-j}$ for some $j \in\{1,2\}$ and $u^{-j} \leq 2 u^{j}$, then two types of coalition perfect equilibria exist:

1. (monopoly equilibria with zero profits) $\exists k \in\{A, B\}$ such that all consumers join network $\tau_{k}, p_{k}^{1}=-p_{k}^{2}$ and $p_{k}^{j} \in\left[-u^{-j}, u^{j}-u^{-j}\right]$

2. (symmetric equilibria with zero profits) $N_{A}^{1}=N_{A}^{2}=N_{B}^{1}=N_{B}^{2}=1 / 2$, $p_{A}^{1}=p_{B}^{1}=-p_{A}^{2}=-p_{B}^{2}$ and $p_{k}^{j} \in\left[\frac{-u^{-j}}{2}, u^{j}-u^{-j}\right]$

- If $u^{j}<u^{-j}$ for some $j \in\{1,2\}$ and $u^{-j}>2 u^{j}$, then only one type of coalition perfect equilibrium exists:

(monopoly equilibria with zero profits) $\exists k \in\{A, B\}$ such that all consumers join network $\tau_{k}, p=-p_{k}^{2}$ and $p_{k}^{j} \in\left[-u^{-j}, u^{j}-u^{-j}\right]$.

\footnotetext{
${ }^{23}$ this is why Caillaud and Jullien[01] obtain a similar result for equilibria in which both firms are active
} 
The above linear specification gives an opportunity for a direct comparison with the predictions of Caillaud and Jullien[01a] in the case of asymmetric sides, since that is exactly the context of their investigation. By assuming monotonicity of the demand function, they obtain the same set of equilibria with two active firms. On the other hand, their refinement selects a larger set of equilibria with one active firm, including equilibria in which the active firm gets positive profits. Furthermore, full participation is an extra assumption in their model, while it is a result in our paper.

\subsection{The general case}

The next example shows that, as opposed to the case of homogeneous consumers, price competition does not necessarily drives profits to zero if consumers are heterogeneous. The example also points out that consumers with different reservation values might join different networks and pay different prices in equilibrium, even in the absence of product differentiation.

Claim 2 Assume $g_{i}^{j}\left(N^{-j}\right)=N^{-j} \cdot u_{i}^{j} \forall j=1,2$ and $i \in[0,1]$. Assume that on both sides of the market, a mass of consumers with measure 0.4 have reservation value 2.55 ('I' types), a mass of consumers with measure 0.15 have reservation value 0.51 ('II' types), a mass of consumers with measure 0.1 have reservation value 0.46 ('III' types), while a mass of consumers with measure 0.35 have reservation value 0.15 (' $I V$ ' types). Then there exists a coalition perfect equilibrium in which one firm charges a price of 0.31 on side 1 and -0.2 on side 2 , while the other firm charges -0.2 on side 1 and 0.31 on side 2. All type ' $I$ ' consumers on side 1 and type ' $I I$ '- ' $I V$ ' consumers on side 2 join the first firm, while all type ' $I$ ' consumers on side 2 and type 'II'- 'IV' consumers on side 1 join the second firm.

Notice that in this profile both firms get a profit of $0.31 \times 0.4-0.2 \times 0.6=$ 0.04, which is strictly positive. Furthermore, in the described equilibrium the firms charge different prices, and consumers on the same side of the market with different reservation values end up paying different prices for the market good, despite the fact that reservation prices are private information of the consumers.

Every consumer on both sides of the market joins some network. Type 'I' consumers on both sides of the market pay a registration fee of 0.31 for 
joining a network, and in equilibrium they face a measure of 0.6 consumers from the other side of the market. All other consumers on both sides of the market are subsidized, they pay a registration fee of -0.2 . In the equilibrium they face only a measure of 0.4 consumers from the other side of the market.

This equilibrium structure is similar to the equilibria in the previous section, in which the monopolist achieved price discrimination by operating two networks. In particular, one network is cheaper on one side of the market, while the other one is cheaper on the other side. A larger fraction of consumers, those having relatively low reservation values, join the cheap network sides, which makes it worthwhile for the remaining, high reservation value, consumers to join the expensive network sides. These similarities are consequences of assuming that after every price announcement consumers play some coalitionally rationalizable Nash equilibrium. In the monopoly case it is never in the interest of the firm to establish two networks that are priced equally, since that would just split consumers into two networks, generating less consumer surplus and therefore less profit. In the duopoly case there cannot be a coalition perfect equilibrium with positive profits and equally priced networks, because of the usual Bertrand competition undercutting argument. Therefore in both cases, for different reasons, the two networks have to be priced differently.

The intuition why competition does not drive profits down to zero in the above example is that with heterogeneous consumers deviation strategies based on undercutting, which are always effective due to the assumption of coalitional rationalizability, are not necessarily profitable. For example if $B$ announces slightly smaller prices than the equilibrium prices of firm $A$ then coalitional rationalizability implies that all type 'I'-'III' from side 1 , and all consumers from side 2 join its network. But the highest profit $B$ can achieve this way is strictly smaller than the equilibrium profit of $B$. The reason is that the proposed undercutting increases the number of consumers joining the network by a larger amount on the side where the price is negative.

The same intuition applies to "divide and conquer" type strategies. A firm can lower its price so that it makes it a dominant choice for some type of consumers to join its network and then it can charge a high price on the other side of the market and still make sure that some consumers join its network on that side as well. But if consumers are heterogeneous, then the proportion of consumers who are willing to pay the increased price on the latter side might be too low to compensate for the costs associated with lowering the price (increasing the subsidy) on the first side. 
Theorem 7 establishes that the basic features of the above example hold for any coalition perfect equilibrium in which some firm's profit is positive, for any game with two firms.

Theorem 7 Suppose that in a coalition perfect equilibrium $\pi_{k}>0$ for some $k \in\{A, B\}$. Then (1) $N_{k}^{j}>0 \forall j \in\{1,2\}$ and $k \in\{A, B\}$; (2) $\exists$ $j \in\{1,2\}$ such that $p_{A}^{j}>p_{B}^{j}, p_{A}^{-j} \leq p_{B}^{-j}, N_{A}^{j} \leq N_{B}^{j}$ and $N_{A}^{-j}>N_{B}^{-j}$.

In all these equilibria both firms have to be active and firm $A$ 's network has to be (weakly) more expensive and smaller on one side of the market and (weakly) cheaper and larger on the other than firm B's network. Furthermore, the two networks have to be asymmetric in the sense that on at least one side the networks charge different prices and on at least one side a different fraction of consumers choose $A$ 's network than $B$ 's.

We conclude the section by establishing that just like in the case of a monopolist network provider, enough heterogeneity among the consumers is needed for the existence equilibria with two asymmetric networks (and therefore for the existence of equilibria with nonzero profits). The next theorem is an extension of Theorem 5 to the case of nearly homogeneous consumers, provided that consumers' utility functions are weakly convex.

Assume that $g_{i}^{j}$ is weakly convex for every $j=1,2$ and $i \in[0,1]$.

Theorem 8 If $u_{i}^{j} / u_{i^{\prime}}^{j} \leq 4 / 3$ for every $j=1,2$ and $i, i^{\prime} \in[0,1]$ then $\pi_{A}=\pi_{B}=0$. Furthermore, there can be two types of coalition perfect equilibria:

1. $\exists k \in\{A, B\}$ such that $N_{k}^{j}=0 \forall j=1,2$ and $i \in[0,1]$

2. $N_{A}^{j}=N_{B}^{j}$ and $p_{A}^{j}=p_{B}^{j} \forall j \in\{1,2\}$

\section{Discussion}

In this section, we discuss how the results of the paper would be affected by changing different assumptions we made in the model. 


\subsection{Positive marginal cost}

If firms face a positive constant marginal cost, all the qualitative results still hold, with one exception. If the marginal cost is higher than a certain threshold, then even if every consumer's reservation value is still higher than the marginal cost, coalitional rationalizability does not exclude the possibility that in price competition between two firms consumers do not join any network in equilibrium. The reason is that if marginal costs are high, then the average price charged on consumers is high and ex-ante coordination to join some network becomes harder.

\subsection{Multi-homing}

In some two-sided markets network choices are naturally mutually exclusive, at least over a given period of time. For example people looking for a date can only be in one entertainment facility at a time. In other contexts consumers can join multiple platforms, which is called multi-homing in the literature. The qualitative conclusions of the paper remain valid if we allow for multi-homing. In particular if there are multiple active networks in coalition perfect equilibrium that are not equally priced then it has to be that one network is cheaper and larger on one side of the market and the other network is cheaper and larger on the other side. If consumers are homogeneous, then it still holds that in every coalition perfect equilibrium both firms get zero profit. On the other hand firms can have positive profits in price competition if consumers are heterogeneous, the intuition being the same as in Section 7. Finally, multi-homing does not change the result that a monopolist might find it more profitable to operate two networks rather than one. In fact, if multi-homing is allowed, then the high reservation value consumers join multiple networks, increasing the monopolist's revenue. This makes operating two networks more attractive and therefore there is a larger set of games in which the monopolist runs two networks in coalition perfect equilibrium.

\subsection{Conflict of interest among consumers on the same side}

The assumption that a consumer's utility is not affected by the number of consumers from the same side of the market who join the same platform as she does can be restrictive in a variety of contexts. If the networks are matchmaking services or auction sites, then people on the same side of the market might competite for the same transactions. In other contexts 
transactions are non-rival goods, validating our assumption of no conflict of interest on the same side.

If consumers are homogeneous, it is possible to partially relax the assumption of no conflict of interest on the same side. In particular, it is enough to assume no conflict of interest on the same side only if every consumer from the other side is present at the same network, for the main qualitative conclusions of the paper to remain valid. ${ }^{24}$ In all other cases consumers' utilities might depend negatively on the number of consumers from the same side joining the same network. One scenario that validates this assumption is if there exist ideal matches in the market, in which case two consumers from the same side are competitors only if their ideal partners from the other side of the market are not present at their network (which cannot happen if all consumers from the other side are present).

\subsection{More than two firms}

With more than two firms operating on the market the analysis of the price competition game becomes complicated and therefore omitted from this paper. However, we note that there can exist coalition perfect equilibria with multiple asymmetric networks in the case of more than two firms too. In fact, in general there is a wider range of coalition perfect equilibria. The intuition behind this is that coordination among consumers is more difficult if there are more than two firms. Formally, coalitional rationalizability puts less restriction on what can happen in consumer subgames. We plan to investigate the effect of the number of firms in the market on the range of equilibria in a future project.

\section{Conclusions and possible extensions}

This paper analyzes pricing decisions of firms and platform choices of consumers on two-sided markets with network externalities, assuming that groups of consumers can coordinate their choices if coordination is focal. A key feature of the analysis is that consumers are allowed to be heterogeneous with respect to their willingness to pay for the network good. To keep the analysis tractable, several simplifying assumptions are made in other dimensions though. Section 8 discusses the consequences of relaxing some of these, but there are several other extensions that would make the

\footnotetext{
${ }^{24}$ See the previous version of our paper for a formal investigation of this.
} 
model more realistic in important settings. Besides registration fees, in several contexts firms might be able to charge usage fees, fees for successful matches, or more complicated pricing instruments like contingent offers. In other two-sided markets, for example the market for health insurance, adverse selection is a central problem. Our model assumes that serving every consumer induces the same marginal cost to the firm and therefore abstracts away from this issue. Finally, there are contexts in which consumers are not ex ante symmetric with respect to the network externality they generate (their "attractiveness" to consumers on the other side). Some of these directions are addressed in the existing literature, others are left for future research.

\section{Appendix}

Some extra notation for the Appendix.

Let $C=C^{1} \cup C^{2}$.

For every $D \subset C$ such that $\left\{i: C^{i} \in D\right\}$ is measurable with respect to the Lebesgue measure, let $N(D)=\int_{C^{i} \in D} d i$.

Let $S_{A}$ denote the set of strategies of player $A, S_{B}$ the set of strategies of player $B$ and $S_{i}^{j}$ the set of strategies of $C_{i}^{j}$ for $j=1,2$ and $i \in[0,1]$. Note that strategies in $S_{i}^{j}$ specify actions for $C_{i}^{j}$ after any history of length 2 . Let $S^{c}=\underset{i \in[0,1]}{\times} S_{i}^{1} \underset{i \in[0,1]}{\times} S_{i}^{2}$

For any game, let $\Gamma^{c}$ be the set of all subgames that start in the third stage. We refer to elements of $\Gamma^{c}$ as consumer subgames.

Moreover, let $c_{i}^{j}$ denote the action choice of consumer $i$ on side $j$.

Finally, for every $s \in S, k \in F, j \in\{1,2\}, n=1, \ldots, n_{k}$ and $i \in[0,1]$ let $n_{k}(s), \pi_{k}(s), p_{k, n}^{j}(s), N_{k, n}^{j}(s)$ and $c_{i}^{j}(s)$ denote the realized $n_{k}, \pi_{k}, p_{k, n}^{j}$, $N_{k, n}^{j}$ and $c_{i}^{j}$ if $s$ is played

Lemma 1 Let $G^{c}=\left(C, S^{c}, u^{c}\right) \in \Gamma^{c}(G)$. Then $\exists s \in S^{c}$ such that $s$ is a coalitionally rationalizable Nash equilibrium of $G^{c}$.

Proof of Lemma 1 For any $A \subset S^{c}$ such that $A=\underset{j=1,2}{\times} \underset{i \in[0,1]}{\times} A_{i}^{j} \neq \emptyset$ let $\digamma(A)$ be the collection of supported restrictions in $S^{c}$ given $A$. Let $A^{0}, A^{1}, \ldots$ be such that $A^{0}=S^{c}$ and $A^{k}=\underset{B \in \digamma\left(A^{k-1}\right)}{\cap} B \forall k \geq 1$. Note that $A^{*}=\lim _{k \rightarrow \infty} A^{k}$ is the set of coalitionally rationalizable strategies in $G^{c}$. 
Let $k \geq 0$ and assume $A^{k} \neq \emptyset$. For every $i \in[0,1]$ and $j=1,2$ let $\bar{u}_{i}^{j}(k)=\sup _{\omega_{-i, j} \in \Omega_{-i, j}\left(A^{k}\right), a_{i, j} \in A_{i, j}^{k}} u_{i, j}^{c}\left(a_{i, j}, \omega_{-i, j}\right)$. Let $\left(a_{i, j}^{m}, \omega_{-i, j}^{m}\right)_{m=1,2, \ldots}$ be such that $a_{i, j}^{m} \in A_{i, j}^{k}$ and $\omega_{-i, j}^{m} \in \Omega_{-i, j}\left(A^{k}\right) \forall m \geq 1$, and $u_{i, j}^{c}\left(a_{i, j}^{m}, \omega_{-i, j}^{m}\right) \rightarrow \bar{u}_{i}^{j}(k)$ as $m \rightarrow \infty$. Since $A_{i, j}^{k}$ is finite, $\left(a_{i, j}^{m}\right)$ has a subsequence $\left(a_{i, j}^{m_{n}}\right)$ such that $\lim _{m_{n} \rightarrow \infty} a_{i, j}^{m_{n}}=a \in A_{i, j}^{k}$. Then by the definition of supported restriction $a \in B_{i, j}$ for every $B \subset A^{k}$ such that $B$ is a supported restriction in $G^{c}$ given $A^{k}$. Since $i$ and $j$ were arbitrary, this implies $A^{k+1} \neq \emptyset$. Then by induction $A^{0}=S^{c} \neq \emptyset$ implies $A^{*} \neq \emptyset$.

Note that $\left(S^{c}\right)_{i}^{j}=\left(S^{c}\right)_{i^{\prime}}^{j^{\prime}} \equiv \bar{S}^{c} \forall i, i^{\prime} \in[0,1]$ and $j, j^{\prime} \in\{1,2\}$. Order pure strategies in $\bar{S}^{c}$ any way, such that $\bar{S}^{c}=\left\{a_{1}, \ldots, a_{n}\right\}$. Define $x(s)$ : $\bar{S}^{c} \rightarrow R^{2 n}$ such that $x_{k}(s)=N\left(C_{i}^{1} \in C^{1}: c_{i}^{1}(s)=a_{k}\right) \forall i \in 1, \ldots, n$ and $x_{k}(s)=N\left(C_{i}^{2} \in C^{2}: c_{i}^{2}(s)=a_{k-n}\right) \forall i \in n+1, \ldots, 2 n$.

Let $\Theta=\left\{\theta \in R^{2 n}: \exists s \in A^{*}\right.$ s.t. $\left.x(s)=\theta\right\}$. It is easy to establish that $\Theta$ is a nonempty, compact and convex subset of $R^{2 n}$. For every $\theta \in \Theta$, $i \in[0,1]$ and $j=1,2$ let $B R_{i}^{j}(\theta)=\left\{a \in \bar{S}^{c}: \exists s \in S\right.$ s.t. $x(s)=\theta$ and $\left.a \in B R_{i}^{j}\left(s_{-j, i}\right)\right\}$. Now define the correspondence $F: \Theta \rightarrow R^{2 n}$ such that $F(\theta)=\left\{y: \exists s \in S^{c}\right.$ s.t. $s_{i}^{j} \in B R_{i}^{j}(\theta)$, and $\left.y=x(s)\right\}$. It is straightforward to establish that $B R_{i}^{j}\left(s_{-j, i}\right) \subset\left(A^{*}\right)_{i}^{j} \forall i \in[0,1]$ and $j=1,2$. This implies that $F(\theta) \subset \Theta \forall \theta \in \Theta$, therefore $F$ is a correspondence from $\Theta$ to itself. Note that $F$ is nonempty valued, since $\bar{S}^{c}$ is finite, so the best response correspondence is nonempty valued. Furthermore, if $s, t \in \bar{S}^{c}$ are such that $s_{i}^{j}, t_{i}^{j} \in B R_{i}^{j}(\theta)$ for some $\theta \in \Theta$, then $z_{i}^{j} \in B R_{i}^{j}(\theta)$ for every $z \in \bar{S}^{c}$ for which it holds that $\forall i \in[0,1]$ and $j=1,2$ either $z_{i}^{j}=s_{i}^{j}$ or $z_{i}^{j}=t_{i}^{j}$. This implies that $F$ is convex valued. Finally, since for every $i \in[0,1]$ and $j=1,2 g_{i}^{j}$ is continuous, it holds that for every $i \in[0,1]$ and $j=1,2 B R_{i}^{j}(\theta)$ is upper hemicontinuous, which implies that $F$ is upper hemicontinuous.

The above imply that all the conditions for Kakutani's fixed point theorem hold for $F$, therefore it has a fixed point $\theta^{*}$. That implies $\exists s^{*} \in A^{*}$ such that $x\left(s^{*}\right)=\theta^{*}$ and $\left(s^{*}\right)_{i}^{j} \in B R_{i}^{j}\left(\theta^{*}\right) \forall \theta \in \Theta, i \in[0,1]$ and $j=1,2$. This implies $\left(s^{*}\right)_{i}^{j} \in B R_{i}^{j}\left(s_{-j, i}^{*}\right) \forall \theta \in \Theta, i \in[0,1]$ and $j=1,2$, which establishes that $s^{*}$ is a coalitionally rationalizable Nash equilibrium. QED.

Proof of Theorem 1 Let $\pi_{A}(s)=\pi$. If $\pi=0$ the claim is trivial, since in every Nash equilibrium and therefore in every coalition perfect Nash equilibrium the firm has to get nonnegative profit (since announcing prices above 0 guarantees that).

Suppose now that $\pi>0$. That implies that at least on one side of the market the monopolist charges a strictly positive profit and has a strictly 
positive market share.

Let $\widehat{C^{j}}(s)=\left\{C_{i}^{j}: c_{i}^{j}(s)=A\right\}$ for $j=1,2$. Then for $C_{i}^{j} \in \widehat{C^{j}}(s)$ and $N^{j} \in[0,1]$ it holds that $g_{i}^{j}\left(N^{-j}\right)-p_{A}^{j}(s) \geqslant 0$ (note that $g_{i}^{j}\left(N_{A}^{-j}(s)\right.$ ) is constant in $\left.N^{j}\right)$. Then for every $\varepsilon>0$ and $C_{i}^{j} \in \widehat{C^{j}}(s)$ it holds that $g_{i}^{j}\left(N_{A}^{-j}(s)\right)-p_{A}^{j}(s)+\varepsilon>0$, which implies that after a price announcement of $\left(p_{A}^{1}(s)-\varepsilon, p_{A}^{2}(s)-\varepsilon\right)$ joining the network is a supported restriction for $\widehat{C^{1}}(s)$ and $\widehat{C^{2}}(s)$.

If $p_{A}^{j}(s)>0$ for $j=1,2$, then it has to be the case that $N_{A}^{j}(s) \geq$ 0 and $\operatorname{Max}\left\{N_{A}^{j}(s), N_{A}^{-j}(s)>0\right\}$. Then the firm can guarantee a profit arbitrarily close to $\pi$ by charging prices $\left(p_{A}^{1}(s)-\varepsilon, p_{A}^{2}(s)-\varepsilon\right)$. If $p_{A}^{j}(s)>0$ and $p_{A}^{-j}(s)=0$ then it has to be the case that $N_{A}^{j}(s)>0$ and $N_{A}^{-j}(s) \geq 0$. In this case, by charging $\left(p_{A}^{1}(s)-\varepsilon, p_{A}^{2}(s)-\varepsilon\right)$ the monopolist gets market shares $N_{A}^{j} \geq N_{A}^{j}(s)$ and $N_{A}^{-j}=1$ and profits arbitrarily close to $\pi$. Finally, if $p_{A}^{j}(s)>0$ and $p_{A}^{-j}(s)=0$ it has to be the case that $N_{A}^{j}(s)$ and $N_{A}^{-j}(s)=1$. Then, by charging $\left(p_{A}^{1}(s)-\varepsilon, p_{A}^{2}(s)-\varepsilon\right)$ the monopolist gets market shares $N_{A}^{j} \geq N_{A}^{j}(s)$ and $N_{A}^{-j}=1$ and again profits arbitrarily close to $\pi$.

That means that if consumers play only coalitionally rationalizable strategies, then the firm can guarantee a profit arbitrarily close to $\pi$ by charging prices $\left(p_{A}^{1}(s)-\varepsilon, p_{A}^{2}(s)-\varepsilon\right)$ where $\varepsilon>0$ is small enough. This implies that it cannot be that $\pi\left(s^{\prime}\right)<\pi$. QED

Proof of Theorem 2 Let $s \in S$ be a coalition perfect equilibrium. If $p^{1}(s), p^{2}(s)<l$ then joining the network is a supported restriction for the coalition of all consumers. The supremum of the profit the firm in this price range is $2 l$ and the firm can get a profit arbitrarily close to it by charging $\left(p^{1}(s), p^{2}(s)\right)=(l-\varepsilon, l-\varepsilon)$ for small enough $\varepsilon>0$. If $p^{1}(s), p^{2}(s)<a h$ then joining the network is a supported restriction for the coalition of consumers that involve the high types from both sides of the market. Therefore the monopolist can guarantee a profit arbitrarily close to $2 a^{2} h$ by charging prices $\left(p^{1}(s), p^{2}(s)\right)=(a h-\varepsilon, a h-\varepsilon)$ for small enough $\varepsilon>0$. If $p^{j}(s)<h$ and $p^{-j}(s)<a l$ for some $j \in\{1,2\}$ then joining the network is a supported restriction for $C^{-j} \cup\left\{C_{i}^{j}: i \in[0, a]\right\}$. Therefore the monopolist can guarantee a profit arbitrarily close to $a(h+l)$ by charging prices $\left(p^{1}(s), p^{2}(s)\right)=$ $(h-\varepsilon, a l-\varepsilon)$ for small enough $\varepsilon>0$.

The above establish that $\pi_{A}(s) \geq \max \left(2 l, 2 a^{2} h, a(h+l)\right)$.

If $p^{j}(s)>h$ for some $j \in\{1,2\}$, then $N^{j}(s)=0$. Then $N^{-j}(s)>0$ only if $p^{-j}(s) \leq 0$. In any case $\pi_{A}(s)<\max \left(2 l, 2 a^{2} h, a(h+l)\right)$. Therefore $p^{j}(s) \leq h$ for $j=1,2$. 
It cannot be that $p^{j}(s) \leq l \forall j \in\{1,2\}$ and $p^{j}(s)<l$ for some $j \in\{1,2\}$, since then $\pi_{A}(s)<2 l$.

If $p^{j}(s)>l \forall j \in\{1,2\}$ then $c_{i}^{j}(s)=\emptyset \forall j=1,2$ and $i \in(a, 1]$. Then it cannot be that $p^{j}(s)>a h$ for some $j \in\{1,2\}$, otherwise $c_{i}^{j}(s)=\emptyset \forall$ $j=1,2$ and $i \in[0,1]$ and therefore $\pi_{A}(s)=0$. Furthermore, it cannot be that $p^{j}(s)<a h$ for some $j \in\{1,2\}$, otherwise $\pi_{A}(s)<2 a^{2} h$.

Suppose now that $p^{j}(s)>l$ and $p^{-j}(s) \leq l$ for some $j \in\{1,2\}$. It cannot be that $p^{-j}(s)<a l$ since then $\pi_{A}(s)<a(l+h)$. If $p^{-j}(s)>a l$, then $p^{j}(s)>a h$ or $p^{-j}(s)>a h$ implies $\pi_{A}(s)=0$. Then $p^{j}(s)<a h$ or $p^{-j}(s)<a h$ implies $\pi_{A}(s)<2 a^{2} h$. Finally, $p^{j}(s)=a h$ and $p^{-j}(s)=a h$ contradict that $p^{j}(s)>l$ and $p^{-j}(s) \leq l$. This concludes that $p^{-j}(s)=a l$. Then $p^{j}(s)=h$, otherwise $\pi_{A}(s)<a(l+h)$.

Consider first the case that $a h \geqslant l$. If $p^{j}(s) \geq a h$ then only high types can join the network in equilibrium. Furthermore, consumers on side $\mathrm{j}$ only join in equilibrium if at least some low types join the network from the other side. For that to be possible in equilibrium, it has to be the case that $p^{-j}(s) \leq a l$. The above imply that if $j(s)>h$ for $j=1$ or $j=2$ then $\pi(s) \leq a h+a l$ But note that the firm can get a profit arbitrarily close to this amount by charging $(h-\varepsilon, a l-\varepsilon)$ for small enough $\varepsilon>0$, since then joining the network is a supported restriction for the coalition of consumers involving all high types on side 1 and all consumers on side 2 .

Consider now the case that $l>a h$. If ${ }^{j}(s)>l$ for $j=1$ or $j=2$ the same arguments as above establish that $\pi(s) \leq a h+a l$, but the monopolist can get a profit arbitrarily close to $a h+a l$ by charging $(h-\varepsilon, a l-\varepsilon)$ for small enough $\varepsilon>0$.

This concludes that $\pi(s) \leq \max \left(2 l, 2 a^{2} h, a h+a l\right)$, but if consumers play only coalitionally rationalizable strategies then the monopolist can always guarantee a profit arbitrarily close to $\max \left(2 l, 2 a^{2} h, a h+a l\right)$. But then it has to be the case that in every coalition perfect equilibrium $\pi(s)=$ $\max \left(2 l, 2 a^{2} h, a h+a l\right)$. This establishes that the prices charged by the monopolist are either $(l, l)$ or $(a h, a h)$ or $(h, a l)$ or $(a l, h)$ in any coalition perfect equilibrium, and in the first case $c_{i}^{1}(s)=c_{i}^{2}(s)=A \forall i \in[0,1]$, in the second case $c_{i}^{1}(s)=c_{i}^{2}(s)=A \forall i \in[0, a]$ and $c_{i}^{1}(s)=c_{i}^{2}(s)=\emptyset \forall i \in(a, 1]$ and in the third case either $c_{i}^{1}=A \forall i \in[0, a], c_{i}^{1}=A \forall i \in(a, 1]$ and $c_{i}^{2}=A \forall$ $i \in[0,1]$ or $p^{1}(s)=a l, p^{2}(s)=h, c_{i}^{1}=A \forall i \in[0,1], c_{i}^{1}=A \forall i \in[0, a]$ and $c_{i}^{1}=\emptyset \forall i \in(a, 1]$.

The above imply that if $2 l>\max \left(2 a^{2} h, a h+a l\right)$ then $p^{j}(s)=l$ and $N^{j}(s)=1 \forall j \in\{1,2\}$. If $2 a^{2} h>\max (2 l, a h+a l)$ then $p^{j}(s)=a h$ and $N^{j}(s)=a \forall j \in\{1,2\}$. And if $a h+a l>\max \left(2 l, 2 a^{2} h\right)$ then $p^{j}(s)=h$, 
$p^{-j}(s)=a l, N^{j}(s)=a$ and $N^{-j}(s)=1$ for some $j \in\{1,2\}$.

Suppose $2 a^{2} h>a l+a h$. Since $a>0$, this is equivalent to $(2 a-1) h>l$. The latter implies $a^{2} h>l$ since $a^{2} h-(2 a-1) h=(a-1)^{2} h>0$. Therefore $(2 a-1) h>l$ implies that $2 a^{2} h>\max (2 l, a h+a l)$.

Suppose now that $a h+a l<2 l$. It is equivalent to $l>\frac{a}{2-a} h$. The latter implies $l>a^{2} h$ since $\frac{a}{2-a} h-a^{2} h=a h \frac{1-2 a+a^{2}}{2-a}>0$. Therefore $2 a^{2} h<2 l$. This establishes that if $l>\frac{a}{2-a} h$ then $2 l>\max \left(2 a^{2} h, a h+a l\right)$.

Note that $(2 a-1) h<\frac{a}{2-a} h$. If $l \in\left((2 a-1) h, \frac{a}{2-a} h\right)$ then $2 a^{2} h<a l+a h$ and $a h+a l>2 l$ and therefore $a h+a l>\max \left(2 l, 2 a^{2} h\right)$.

Let $G^{1}=\left(I, S^{1}, u^{1}\right) \in \Gamma^{c}$ be the subgame following price announcements (ah,ah) and let $s^{1} \in S^{1}$ be such that $\left(s^{1}\right)_{i}^{1}=\left(s^{1}\right)_{i}^{2}=A \forall i \in[0, a]$ and $\left(s^{1}\right)_{i}^{1}=\left(s^{1}\right)_{i}^{2}=\emptyset \forall i \in(a, 1]$. Let $G^{2}=\left(I, S^{2}, u^{2}\right) \in \Gamma^{c}$ be the subgame following price announcements $(h, a l)$ and let $s^{2} \in S^{2}$ be such that $\left(s^{1}\right)_{i}^{1}=A$ $\forall i \in[0, a],\left(s^{1}\right)_{i}^{1}=\emptyset \forall i \in(a, 1]$ and $\left(s^{1}\right)_{i}^{2}=A \forall i \in[0,1]$. Let $G^{3}=$ $\left(I, S^{3}, u^{3}\right) \in \Gamma^{c}$ be the subgame following price announcements $(l, l)$ and let $s^{3} \in S^{3}$ be such that $\left(s^{3}\right)_{i}^{1}=\left(s^{3}\right)_{i}^{2}=A \forall i \in[0,1]$. It is straightforward to establish that for $k=1,2,3 s^{k}$ is a coalitionally rationalizable Nash equilibrium in $G^{k}$. Let now $s_{-A} \in S_{-A}$ be any profile that specifies $s^{k}$ in $G^{k}$ for every $k=1,2,3$ and specifies some arbitrary coalitionally rationalizable Nash equilibrium in every other $G^{c} \in \Gamma^{c}$. By Lemma 1 there exists a profile like that. Let $s_{A}$ be such that $p_{A}\left(s_{A}\right)=(a h, a h)$. Let $s_{A}^{\prime}$ be such that $p_{A}\left(s_{A}^{\prime}\right)=(h, a l)$. And let $s_{A}^{\prime \prime}$ be such that $p_{A}\left(s_{A}^{\prime \prime}\right)=(l, l)$. If $\frac{l}{h}=2 a-1$ then $2 a^{2} h=a h+a l=\max \left(2 l, 2 a^{2} h, a h+a l\right)$. The above then establish that both $\left(s_{A}, s_{-A}\right)$ and $\left(s_{A}^{\prime}, s_{-A}\right)$ are coalition perfect equilibria. If $\frac{l}{h}=\frac{a}{2-a}$ then $2 l=a h+a l=\max \left(2 l, 2 a^{2} h, a h+a l\right)$. The above then establish that both $\left(s_{A}^{\prime}, s_{-A}\right)$ and $\left(s_{A}^{\prime \prime}, s_{-A}\right)$ are coalition perfect equilibria. QED

Proof of Theorem 3 If $s_{-A} \in S_{-A}$ is such that consumers play a coalitionally rationalizable Nash equilibrium in every consumer subgame, then in the subgame following $n_{A}\left(s_{A}, s_{-A}\right)=2$ and $p_{1}^{1}=p_{2}^{2}=l a-\varepsilon$, $p_{1}^{2}=p_{2}^{1}=l a+(1-a) h-2 \varepsilon(\varepsilon>0)$, it has to hold that $n_{i}^{1}=2, n_{i}^{2}=1$ $\forall i \in[0, a]$ and $n_{i}^{1}=1, n_{i}^{2}=2 \forall i \in(a, 1]$. To see this, define $A \subset S$ such that $A=\underset{i \in[0,1], j=1,2}{\times} A_{i}^{j}$ and $A_{i}^{j} \equiv\{\emptyset, 1,2\} \forall i \in[0, a], j=1,2, A_{i}^{1} \equiv\{\emptyset, 1\}$ $\forall i \in(a, 1]$ and $A_{i}^{2} \equiv\{\emptyset, 2\} \forall i \in(a, 1]$. Also define $B \subset S$ such that $B=\underset{i \in[0,1], j=1,2}{\times} B_{i}^{j}$ and $B_{i}^{1} \equiv\{2\} \forall i \in[0, a], B_{i}^{2} \equiv\{1\} \forall i \in[0, a], j=1,2$, $B_{i}^{1} \equiv\{1\} \forall i \in(a, 1]$ and $A_{i}^{2} \equiv\{2\} \forall i \in(a, 1]$. First note that $A_{i}^{j} \times S_{-1, i}$ is a supported restriction by $C_{i}^{j}$ given $S \forall i \in[0,1]$ and $j=1,2$ (since strategies in $S_{i}^{j} / A_{i}^{j}$ are never best responses for $C_{i}^{j}$ ). Next, $B$ is a supported restriction 
given $A$ by $C^{1} \cup C^{2}$ since it gives the best possible payoff to every consumer in this subgame, given $A$. Therefore $n_{i}^{1}=2, n_{i}^{2}=1 \forall i \in[0, a]$ and $n_{i}^{1}=1$, $n_{i}^{2}=2 \forall i \in(a, 1]$ is the only coalitionally rationalizable strategy in the above subgame.

Since $\varepsilon$ can be arbitrarily small positive, the above establishes that if $s \in S$ is a coalition perfect equilibrium, then $\pi_{A}(s) \geq 2(l a+(1-a) a h) \equiv \pi^{*}$.

Suppose $s_{-A} \in S_{-A}$ is such that consumers play a coalitionally rationalizable Nash equilibrium in every consumer subgame and $\exists \widehat{s}_{A} \in S_{A}$ such that $\pi_{A}\left(\widehat{s}_{A}, s_{-A}\right) \geq \pi^{*}$ and it is not the case that $n_{A}\left(\widehat{s}_{A}, s_{-A}\right)=2$, and $p_{j}^{1}\left(\widehat{s}_{A}, s_{-A}\right)=p_{-j}^{2}\left(\widehat{s}_{A}, s_{-A}\right)=l a, p_{j}^{2}\left(\widehat{s}_{A}, s_{-A}\right)=p_{-j}^{1}\left(\widehat{s}_{A}, s_{-A}\right)=l a+(1-a) h$ for some $j=1,2$.

Let $s=\left(\widehat{s}_{A}, s_{-A}\right)$.

First suppose $n_{A}(s)=1$. If $l \in\left((4 a-1) h, \frac{a}{2-a} h\right)$, then by Theorem $4 \pi_{A}(s) \leq(l+h) a$. But for $l>(4 a-1) h$ it holds that $(l+h) a<2(l a+$ $(1-a) a h) \equiv \pi^{*}$, a contradiction. If $l \in\left(\left(\frac{a}{2-a} h, \frac{a(1-2 a)}{1-a} h\right)\right.$, then by Theorem $4 \pi_{A}(s) \leq 2 l$. But $l<\frac{a(1-2 a)}{1-a} h$ implies $2 l<2(l a+(1-a) a h) \equiv \pi^{*}$, a contradiction.

Therefore $n_{A}(s)=2$.

It cannot be that $N_{k}^{j}=0$ for some $j=1,2$ and $k=1,2$ since then either $N_{k}^{-j}(s)=0$ or $p_{k}^{-j}(s) \leq 0$ (otherwise consumers choosing network $k$ in $s$ would get negative utility, contradicting the assumption on $s_{-A}$ ). In either case $\pi_{A}(s)$ is smaller or equal to the supremum of profits attainable by a strategy in which $A$ operates only one network. Then, as established above, $\pi_{A}(s)<\pi^{*}$. Therefore $N_{k}^{j}>0 \forall j=1,2$ and $k=1,2$.

Let $H^{j}=\left\{C_{i}^{j}: i \in[0, a]\right\}$ and $L^{j}=\left\{C_{i}^{j}: i \in(a, 1]\right\} \forall j=1,2$.

Let $X_{k}^{j}=\left\{C_{i}^{j}: n_{i}^{j}(s)=k\right\} \forall j=1,2$ and $k=1,2$.

First we establish that it cannot be that for some $j=1,2$ both $X_{1}^{j} \cap L^{j}=$ $\emptyset$ and $X_{2}^{j} \cap L^{j}=\emptyset$. If $X_{1}^{j} \cap L^{j}=\emptyset$ and $X_{2}^{j} \cap L^{j}=\emptyset \forall j=1,2$ then $\pi_{A}(s)<$ $2 a^{2} h<\pi^{*}$. Otherwise, w.l.o.g. assume $X_{1}^{2} \cap L^{2}=\emptyset$ and $X_{2}^{2} \cap L^{2}=\emptyset$ and $X_{2}^{1} \cap L^{1} \neq \emptyset$. Then consider a deviation $s^{\prime}$ by the firm such that $n_{A}\left(s^{\prime}\right)=1$, $p^{1}\left(s^{\prime}\right)=\max \left(0, p_{1}^{1}(s) \frac{N_{1}^{2}+N_{2}^{2}}{N_{2}^{2}}-\varepsilon\right)$ and $p^{2}\left(s^{\prime}\right)=\max \left(0, p_{2}^{2}(s)-\varepsilon\right)$. In the subgame following the above prices it is a supported restriction for $X_{1}^{1} \cup$ $X_{2}^{1} \cup X_{1}^{2} \cup X_{2}^{2}$ (note that $X_{2}^{1} \cap L^{1} \neq \emptyset$ and therefore $p_{1}^{1}(s) \leq l N_{2}^{2}$ ) to choose 1, which guarantees a profit of at least $\pi^{\prime} \equiv p^{1}\left(s^{\prime}\right)\left(N_{1}^{1}+N_{2}^{1}\right)+p^{2}\left(s^{\prime}\right)\left(N_{1}^{2}+N_{2}^{2}\right)$. Consider now deviation $s^{\prime \prime}$ by the firm such that $n_{A}\left(s^{\prime \prime}\right)=1, p^{1}\left(s^{\prime \prime}\right)=$ $\max \left(0, p_{1}^{2}(s) \frac{N_{1}^{2}+N_{2}^{2}}{N_{1}^{2}}-\varepsilon\right)$ and $p^{2}\left(s^{\prime \prime}\right)=\max \left(0, p_{1}^{2}(s)-\varepsilon\right)$. In the subgame following the above prices it is a supported restriction for $X_{2}^{1} \cup X_{1}^{2} \cup X_{2}^{2}$ to 
choose 1 , which guarantees a profit of at least $\pi^{\prime \prime} \equiv p^{1}\left(s^{\prime \prime}\right) N_{2}^{1}+p^{2}\left(s^{\prime \prime}\right)\left(N_{1}^{2}+\right.$ $\left.N_{2}^{2}\right)$. It is straightforward to verify that both $\pi^{\prime} \leq \pi_{A}(s)$ and $\pi^{\prime \prime} \leq \pi_{A}(s)$, and therefore at least one of the above deviations yields higher profit than $\pi_{A}(s)$. And since $n_{A}\left(s^{\prime}\right)=1$ and $n_{A}\left(s^{\prime \prime}\right)=1$, it holds that $\pi^{\prime}<\pi^{*}$ and $\pi^{\prime \prime}<\pi^{*}$.

Next we establish that it cannot be that for some $j=1,2$ both $X_{1}^{j} \cap L^{j} \neq$ $\emptyset$ and $X_{2}^{j} \cap L^{j} \neq \emptyset$. If $X_{1}^{j} \cap L^{j} \neq \emptyset$ and $X_{2}^{j} \cap L^{j} \neq \emptyset \forall j=1,2$ then $p_{k}^{j}(s) \leq l N_{k}^{-j}(s) \forall k=1,2$ and $j=1,2$. Then $\pi_{A}(s)<2 l<\pi^{*}$. Otherwise w.l.o.g. assume $X_{1}^{1} \cap L^{1} \neq \emptyset, X_{2}^{1} \cap L^{1} \neq \emptyset$ and $X_{1}^{2} \cap L^{2} \neq \emptyset$. Then $\pi_{A}(s)<$ $(h+l) N_{1}^{1}(s) N_{2}^{2}(s)+2 l N_{1}^{2}(s) N_{2}^{1}(s)$, since $p_{1}^{1}(s) \leq l N_{2}^{2}(s), p_{2}^{1}(s) \leq l N_{2}^{1}(s)$, $p_{1}^{2}(s) \leq l N_{1}^{1}(s)$ and $p_{2}^{2}(s)<h N_{2}^{1}(s)$. Note that $(h+l) N_{2}^{2}(s)<(h+l) a<\pi^{*}$ and therefore $(h+l) N_{2}^{2}(s)<(h+l) N_{1}^{1}(s) N_{2}^{2}(s)+2 l N_{1}^{2}(s) N_{2}^{1}(s)$. This

implies $(h+l) N_{2}^{2}(s)<2 l N_{1}^{2}(s)<2 l$. Furthermore, $2 l<\pi^{*}$ and therefore $2 l<(h+l) N_{1}^{1}(s) N_{2}^{2}(s)+2 l N_{1}^{2}(s) N_{2}^{1}(s)$. This implies $2 l\left(1-N_{1}^{2}(s) N_{2}^{1}(s)\right)<$ $(h+l) N_{1}^{1}(s) N_{2}^{2}(s)$ which implies $2 l N_{1}^{1}(s)<(h+l) N_{1}^{1}(s) N_{2}^{2}(s)$ which implies $2 l<(h+l) N_{2}^{2}(s)$, a contradiction.

Next we establish that it cannot be that for some $k=1,2$ both $X_{k}^{1} \cap$ $L^{1} \neq \emptyset$ and $X_{k}^{2} \cap L^{2} \neq \emptyset$. Suppose otherwise. Then, as established above, $X_{-k}^{1} \cap L^{1}=\emptyset$ and $X_{-k}^{2} \cap L^{2}=\emptyset$, but $X_{-k}^{1} \neq \emptyset$ and $X_{-k}^{2} \neq \emptyset$. This implies $N_{k}^{-j}(s) l-p_{k}^{j}(s) \geq N_{-k}^{-j}(s) l-p_{-k}^{j}(s) \forall j=1,2$ and $N_{k}^{-j}(s) h-p_{k}^{j}(s) \leq$ $N_{-k}^{-j}(s) h-p_{-k}^{j}(s) \forall j=1,2$, which implies $p_{k}^{j}(s) \leq p_{-k}^{j}(s) \forall j=1,2$. Then by Lemma 1 it has to be that $p_{k}^{j}(s)=p_{-k}^{j}(s) \forall j=1,2$. But since $p_{k}^{j}(s) \leq N_{k}^{-j}(s) l<l \forall j=1,2$, this implies $\pi_{A}(s)<2 l<\pi^{*}$.

Therefore $\exists k \in\{1,2\}$ such that $X_{k}^{1} \cap H^{1}=X_{k}^{1}$ and $X_{-k}^{2} \cap H^{2}=X_{k}^{2}$. W.l.o.g. let $k=1$.

Note that $p_{1}^{2}(s) \leq l N_{1}^{1}$ and $p_{2}^{1}(s) \leq l N_{2}^{2}$ since $X_{1}^{2} \cap L^{2} \neq \emptyset, X_{2}^{1} \cap L^{1} \neq \emptyset$ and by definition no consumer can get negative utility in any subgame if $s$ is played. Then $h N_{1}^{2}-p_{1}^{1}(s) \geq h N_{2}^{2}-p_{2}^{1}(s)$ implies $p_{1}^{1}(s) \leq l N_{2}^{2}+h\left(1-N_{2}^{2}\right)$ and $h N_{2}^{1}-p_{2}^{2}(s) \geq h N_{1}^{1}-p_{1}^{2}(s)$ implies $p_{2}^{2}(s) \leq l N_{1}^{1}+h\left(1-N_{1}^{1}\right)$. This establishes that $\pi_{A}(s) \leq l\left(N_{1}^{1} N_{1}^{2}+N_{2}^{1} N_{2}^{2}\right)+\left(l N_{2}^{2}+h\left(1-N_{2}^{2}\right)\right) N_{1}^{1}+\left(l N_{1}^{1}+\right.$ $\left.h\left(1-N_{1}^{1}\right)\right) N_{2}^{2} \leq l\left(N_{1}^{1}+N_{2}^{2}\right)+h\left(N_{1}^{1}+N_{2}^{2}-2 N_{1}^{1} N_{2}^{2}\right)$.

Note that $\frac{\partial\left(l\left(N_{1}^{1}+N_{2}^{2}\right)+h\left(N_{1}^{1}+N_{2}^{2}-2 N_{1}^{1} N_{2}^{2}\right)\right)}{\partial N_{1}^{1}}=h+l-2 h N_{2}^{2} \geq h+l-2 h a>0$ (since the starting assumptions imply $a<1 / 2$ ). Similarly it holds that $\frac{\partial\left(l\left(N_{1}^{1}+N_{2}^{2}\right)+h\left(N_{1}^{1}+N_{2}^{2}-2 N_{1}^{1} N_{2}^{2}\right)\right)}{\partial N_{2}^{2}}=h+l-2 h N_{1}^{1} \geq h+l-2 h a>0$. Therefore $\pi_{A}(s)<l 2 a+h\left(2 a-2 a^{2}\right)=\pi^{*}$ unless $p_{1}^{2}(s)=p_{2}^{1}(s)=a l, N_{1}^{2}(s)=N_{2}^{1}(s)=$ $1-a, p_{1}^{1}(s)=p_{2}^{2}(s)=l a+h(1-a)$ and $N_{1}^{1}(s)=N_{2}^{2}(s)=a$.

This concludes the claim. QED 
Proof of Theorem 4 Suppose $\exists s \in S$ such that $s$ is a coalition perfect equilibrium, $n_{A}(s)=2$ and $N_{k}^{j}(s)>0 \forall j \in\{1,2\}$ and $k \in\{A, B\}$.

By Lemma 5.1 (see below) $\exists k \in\{1,2\}$ such that $p_{k}^{1}(s) \leq p_{3-k}^{1}(s)$ and $p_{k}^{2}(s) \geq p_{3-k}^{2}(s)$, otherwise $N_{k}^{1}(s)=N_{k}^{2}(s)=0$ for some $k \in\{1,2\}$. Let $l^{1}=\left(\inf _{i \in[0,1]: c_{i}^{j}(s)=k} u_{i}^{1}\right)\left(N_{k}^{2}(s)+N_{3-k}^{2}(s)\right), h^{1}=\left(\inf _{i \in[0,1]: c_{i}^{j}(s)=3-k} u_{i}^{1}\right)\left(N_{k}^{2}(s)+\right.$ $\left.N_{3-k}^{2}(s)\right), l^{2}=\left(\inf _{i \in[0,1]: c_{i}^{j}(s)=3-k} u_{i}^{2}\right)\left(N_{k}^{1}(s)+N_{3-k}^{1}(s)\right)$ and $h^{2}=\left(\inf _{i \in[0,1]: c_{i}^{j}(s)=k} u_{i}^{2}\right)$ $\left(N_{k}^{1}(s)+N_{3-k}^{1}(s)\right)$. Then Nash equilibrium implies $p_{k}^{1}(s) \leq N_{k}^{2}(s) l^{1} /\left(N_{k}^{2}(s)+\right.$ $\left.N_{3-k}^{2}(s)\right), p_{3-k}^{2}(s) \leq N_{k}^{1}(s) l^{2} /\left(N_{k}^{1}(s)+N_{3-k}^{1}(s)\right), p_{3-k}^{1}(s) \leq\left(N_{k}^{2}(s)-N_{k}^{2}(s)\right)$ $h^{1} /\left(N_{k}^{2}(s)+N_{3-k}^{2}(s)\right)+p_{k}^{1}(s)$ and $p_{k}^{2}(s) \leq\left(N_{3-k}^{1}(s)-N_{k}^{1}(s)\right) h^{2} /\left(N_{k}^{1}(s)+\right.$ $\left.N_{3-k}^{1}(s)\right)+p_{3-k}^{2}(s)$. Let $x^{1}=N_{k}^{1}(s) /\left(N_{k}^{1}(s)+N_{3-k}^{1}(s)\right)$ and $x^{2}=N_{3-k}^{2}(s) /$ $\left(N_{3-k}^{2}(s)+N_{k}^{2}(s)\right)$. Then $\pi_{A}(s) \leq x^{2} l^{1}\left(1-x^{1}\right)+x^{1}\left(\left(1-2 x^{2}\right) h^{1}+x^{2} l^{1}\right)+$ $x^{1} l^{2}\left(1-x^{2}\right)+x^{2}\left(\left(1-2 x^{1}\right) h^{2}+x^{1} h^{2}\right)=h^{1} x^{1}+h^{2} x^{2}+l^{1} x^{2}+l^{2} x^{1}-2 h^{1} x^{1} x^{2}-2 h^{2}$ $x^{1} x^{2}$. Taking first order conditions it is easy to verify that the latter expression is maximized at $x_{1}=\frac{h^{2}+l^{1}}{2 h^{1}+2 h^{2}}, x_{2}=\frac{h^{1}+l^{1}}{2 h^{1}+2 h^{2}}$. Substituting these values into the expression yields $\pi_{A}(s) \leq \frac{\left(h^{1}+l^{2}\right)\left(h^{2}+l^{1}\right)}{2\left(h^{1}+h^{2}\right)}$.

Let $\widehat{C}(s)=\left\{C_{i}^{j} \in C: c_{i}^{j}(s) \neq \emptyset\right\}$. Notice that if $s_{A}^{\prime} \in S_{A}$ is such that $n_{A}\left(s_{A}^{\prime}\right)=1$ and $p_{A}^{j}\left(s_{A}^{\prime}\right)=l^{j} /\left(N_{k}^{3-j}(s)+N_{3-k}^{3-j}(s)\right)-\varepsilon \forall j \in\{1,2\}$, where $\varepsilon>$ 0 , then $\pi_{A}\left(s_{A}^{\prime}, s_{A}\right) \geq l^{1}+l^{2}-\varepsilon\left(\sum_{j=1,2 k=1,2} \sum_{k} N_{k}^{j}(s)\right)$, since the assumptions that there is no conflict of interest among consumers on the same side and that $s$ is a Nash equilibrium together guarantee that in the consumer subgame following the above price announcements joining the network is a supported restriction for all players in $\widehat{C}(s)$. Since $s$ is a Nash equilibrium, this implies $\pi_{A}(s) \geq l^{1}+l^{2}$. Therefore $\frac{\left(h^{1}+l^{2}\right)\left(h^{2}+l^{1}\right)}{2\left(h^{1}+h^{2}\right)} \geq l^{1}+l^{2}$.

It is straightforward to verify that for any $h_{1}+h_{2}=h>0$ and $l_{1}+l_{2}=$ $l>0$ the expression $\frac{\left(h_{1}+l_{2}\right)\left(h_{2}+l_{1}\right)}{2\left(h_{1}+h_{2}\right)}-l_{1}-l_{2}$ is maximized at $h_{1}=h_{2}=h / 2$, $l_{1}=l_{2}=l / 2$. In that case $\frac{\left(h_{1}+l_{2}\right)\left(h_{2}+l_{1}\right)}{2\left(h_{1}+h_{2}\right)}-l_{1}-l_{2}=h^{2}-6 h l+l^{2}$. Then $s$ being a Nash equilibrium implies $h^{2}-6 h l+l^{2} \geq 0$. Since $h>l$, this implies $h \geq(3+2 \sqrt{2}) l$. Therefore if $\left(\max _{i \in[0,1]} u_{i}^{j}\right) /\left(\min _{i \in[0,1]} u_{i}^{j}\right)<3+2 \sqrt{2} \forall j \in\{1,2\}$, then $s$ cannot be a Nash equilibrium, a contradiction. QED

Lemma 5.1 Let $G^{c}=\left(C, S^{c}, u^{c}\right)$ be the subgame following price announcements $\left(p_{A}^{1}, p_{A}^{2}, p_{B}^{1}, p_{B}^{2}\right)$. If $p_{A}^{j}<p_{B}^{j} \forall j=1,2$ then $B$ is not coalitionally rationalizable in $G^{c}$ for any $C_{i}^{j} \in C$. If also $p_{A}^{j}<u^{j} \forall j \in\{1,2\}$ then $A$ is the unique coalitionally rationalizable strategy in $G^{c}$ for every $C_{i}^{j} \in C$. Similarly if $p_{B}^{j}<p_{A}^{j} \forall j=1,2$ then $A$ is not coalitionally rationalizable 
in $G^{c}$ for any $C_{i}^{j} \in C$. If also $p_{B}^{j}<u^{j} \forall j \in\{1,2\}$ then $B$ is the unique coalitionally rationalizable strategy in $G^{c}$ for every $C_{i}^{j} \in C$.

Proof of Lemma 5.1 Consider $p_{A}^{j}<p_{B}^{j} \forall j=1$, 2. If $p_{B}^{j}>u^{j}$ for some $j \in\{1,2\}$ then in $G^{c}$ choosing $B$ is not rationalizable for any $C_{i}^{j} \in C$. Observe that $p_{A}^{j} \leq u^{j} \forall j \in\{1,2\}$ implies $p_{A}^{j}<u^{j} \forall j \in\{1,2\}$. For every $C_{i}^{j} \in C$ the maximum utility $C_{i}^{j}$ can expect when joining $B$ is $u^{j}-p_{B}^{j}$. The minimum utility that $C_{i}^{j}$ can expect if every consumer in $C$ joins $A$ is $u^{j}-p_{A}^{j}(s)>u^{j}-p_{B}^{j}$. If $p_{A}^{j}(s)<u^{j} \forall j \in\{1,2\}$ then this implies that joining $A$ is a supported restriction for consumers in $C$, which implies the claim.

The other case is perfectly symmetric. QED

Lemma 5.2 For every $k=1,2$ and $i \in[0,1]$ it holds that $\emptyset$ is not coalitionally rationalizable for $C_{i}^{k}$ in the subgame following price announcements $(0,0,0,0)$.

Proof of Lemma 5.2 Let $\widehat{S}_{i}^{k}=\{A, B\} \forall k=1,2$ and $i \in[0,1]$. Consider the restriction $\widehat{S} \equiv \underset{i \in[0,1]}{\times} \widehat{S}_{i}^{1} \underset{i \in[0,1]}{\times} \widehat{S}_{i}^{2}$ given $S^{c}$ by $C$ in the subgame following price announcements $(0,0,0,0)$. Let $k \in\{1,2\}, i \in[0,1]$ and $\omega_{-k, i} \in$ $\Omega_{-k, i}(\widehat{S})$. Let $n_{A}^{-k}\left(\omega_{-k, i}\right)=\int_{t_{-i} \in S_{-i}} g_{j}\left(C_{j}^{-k} \in C^{-k} / C_{i}^{-k}: t_{j}^{k}(0,0,0,0)=\right.$ A)d $\omega_{-k, i}$ and let $n_{B}^{-k}\left(\omega_{-k, i}\right)=\int_{t_{-i} \in S_{-i}} g_{j}\left(C_{j}^{-k} \in C^{-k} / C_{i}^{-k}: t_{j}^{k}(0,0,0,0)=\right.$ $B) d \omega_{-k, i}$. Since $\omega_{-k, i} \in \Omega_{-k, i}(\widehat{S}), \min \left(n_{A}^{-k}\left(\omega_{-i}\right), n_{B}^{-k}\left(\omega_{-i}\right)\right)>0$. Then playing a best response strategy to $\omega_{-k, i}$ yields a positive expected payoff to $C_{i}^{k}$. Since $U_{i}^{k}(\emptyset)=0 \forall i \in[0,1]$, this implies that the above restriction is supported for $C$ and therefore $\emptyset$ is not a coalitionally rationalizable strategy for any $k=1,2$ and $i \in[0,1]$. QED

Lemma 5.3 Let $s$ be a coalition perfect equilibrium. If $N_{A}^{k}(s)>0$ for some $k=1,2$ and $N_{B}^{1}(s)=N_{B}^{2}(s)=0$ then (i) $p_{A}^{1}(s)=-p_{A}^{2}(s)$, (ii) $p_{A}^{k}(s) \leq u^{k} \forall k=1,2$ and (iii) $N_{A}^{1}(s)=N_{A}^{2}(s)=1$. Similarly if $N_{B}^{k}(s)>0$ for some $k=1,2$ and $N_{A}^{1}(s)=N_{A}^{2}(s)=0$ then (i) $p_{B}^{1}(s)=-p_{B}^{2}(s)$, (ii) $p_{B}^{k}(s) \leq u^{k} \forall k=1,2$ and (iii) $N_{B}^{1}(s)=N_{B}^{2}(s)=1$.

Proof of Lemma 5.3 Note that $N_{B}^{1}(s)=N_{B}^{2}(s)=0$ implies $\pi_{B}(s)=0$. Suppose $p_{A}^{k}(s)>u^{k}$ for some $k=1,2$. Then $N_{A}^{k}(s)=0$ since consumers cannot get negative utility in $s$. Then $N_{A}^{-k}(s)>0$ implies that $p_{A}^{-k}(s) \leq 0$, again because consumers cannot get negative utility in $s$. Since $A$ cannot have negative profit in $s$, this implies $p_{A}^{-k}(s)=0$. Consider the deviation $(u-\varepsilon,-\varepsilon)$ by $B$, where $\varepsilon>0$. In the subgame following this deviation it is a supported restriction for $C^{1} \cup C^{2}$ to play $B$, because that profile yields 
the highest possible payoff in this subgame for every $C_{i}^{k} \in C$, and choosing $A$ or $\emptyset$ yields a strictly smaller payoff than this maximum no matter what strategies other consumers play. Therefore $s_{i}^{k}\left(p_{A}^{1}(s), p_{A}^{2}(s), u-\varepsilon,-\varepsilon\right)=B \forall$ $k=1,2$ and $i \in[0,1]$. Then $B$ 's profit after this deviation is $u-2 \varepsilon$, which is positive for small enough profits, a contradiction. This concludes that $p_{A}^{k}(s) \leq u^{k} \forall k=1,2$.

Suppose now that $p_{A}^{1}(s)+p_{A}^{2}(s)>0$. Consider the deviation $\left(p_{A}^{1}(s)-\right.$ $\left.\varepsilon, p_{A}^{2}(s)-\varepsilon\right)$ by $B$, where $\varepsilon>0$. By lemma $5.1 s_{i}^{k}\left(p_{A}^{1}(s), p_{A}^{2}(s), p_{A}^{1}(s)-\right.$ $\left.\varepsilon, p_{A}^{2}(s)-\varepsilon\right)=B \forall k=1,2$ and $i \in[0,1]$. Then $B$ 's profit after this deviation is $p_{A}^{1}(s)+p_{A}^{2}(s)-2 \varepsilon$, which is positive for small enough $\varepsilon$, a contradiction. This concludes that $p_{A}^{1}(s)+p_{A}^{2}(s) \leq 0$.

Suppose now that $p_{A}^{1}(s)+p_{A}^{2}(s)<0$. This implies $p_{A}^{k}(s)<0$ for some $k=1,2$. Then $N_{B}^{k}(s)=0$ implies $N_{A}^{k}(s)=1$, since $A$ strictly dominates $\emptyset$ for side 1 consumers. But then $p_{A}^{1}(s)+p_{A}^{2}(s)$ implies $\pi_{A}(s)=p_{A}^{1}(s) N_{A}^{1}(s)+$ $p_{A}^{2}(s) N_{A}^{2}(s)<0$, a contradiction. This concludes that $p_{A}^{1}(s)+p_{A}^{2}(s) \leq 0$.

If $p_{A}^{k}(s)<0$ for some $k=1,2$, then $N_{B}^{k}(s)=0$ implies $N_{A}^{k}(s)=1$. Then $\pi_{A}(s) \geq 0$ implies that $N_{A}^{k}(s)=1 \forall k=1,2$.

Consider now $p_{A}^{1}(s)=p_{A}^{2}(s)=0$. Then $\pi_{A}(s)=0$. If $p_{B}^{k}(s)<0$ for some $k=1,2$, then $\emptyset$ is a strictly dominated strategy for side $k$ consumers, and therefore $N_{B}^{k}(s)=0$ implies $N_{A}^{k}(s)=1$. Then choosing $A$ yields utility $u_{-k}>0$ for side $-k$ consumers, and therefore $N_{B}^{-k}(s)=0$ implies $N_{A}^{-k}(s)=1$. Suppose now that $p_{B}^{1}(s)>0$ and $p_{B}^{2}(s)=0$. Then by lemma 5.1 a deviation $\min \left(u-\varepsilon, p_{B}^{1}(s)-\varepsilon\right),-\varepsilon$ by $A$ for $\varepsilon>0$ guarantees that all consumers join $A$, which for small enough $\varepsilon$ yields positive profit for $A$, contradicting that $s$ is an equilibrium. A symmetric argument rules out that $p_{B}^{1}(s)=0$ and $p_{B}^{2}(s)>0$. If $p_{B}^{1}(s)=p_{B}^{2}(s)=0$, then lemma 5.2 implies that $N_{A}^{k}(s)+N_{B}^{k}(s)=1 \forall k=1,2$, and then $N_{B}^{1}(s)=N_{B}^{2}(s)=0$ implies $N_{A}^{1}(s)=N_{A}^{2}(s)=1$. QED

Lemma 5.4 Let $s$ be a coalition perfect equilibrium such that $N_{A}^{k}(s)>0$ for some $k=1,2$ and $N_{B}^{k}(s)>0$ for some $k=1,2$. Then $p_{A}^{1}(s)=p_{B}^{1}(s)=$ $-p_{A}^{2}(s)=-p_{B}^{2}(s)$ and $p_{A}^{k}(s) \leq u^{k} \forall k=1,2$. Moreover, $N_{A}^{1}(s)=N_{A}^{2}(s)=$ $N_{B}^{1}(s)=N_{B}^{2}(s)=1 / 2$.

Proof of Lemma 5.4 Suppose $p_{f}^{k}(s)>u^{k}$ for some $k=1,2$ and $f \in$ $\{A, B\}$. W.l.o.g. assume $p_{A}^{1}(s)>u^{1}$. Then $N_{A}^{1}(s)=0$ and therefore $N_{A}^{2}(s)>0$. This is only compatible with consumers choosing $A$ in $s$ playing a best response and $A$ not getting negative profits if $p_{A}^{2}(s)=0$. Then by lemma 5.1 a price announcement $\left(u^{1}-\varepsilon,-\varepsilon\right)$ by $B$ for $\varepsilon>0$ guarantees that all consumers join $B$, which for small enough $\varepsilon$ yields positive profit for $B$. Therefore $\pi_{A}(s)=0$ and $\pi_{B}(s)>0$. The latter can only be if both 
$N_{B}^{1}(s)>0$ and $N_{B}^{2}(s)>0$, which imply that $p_{B}^{k}(s) \leq u^{k} \forall k=1,2$. Then by Lemma 5.1 a deviation $p_{B}^{1}(s)-\varepsilon, p_{B}^{2}(s)-\varepsilon$ by $A$ for $\varepsilon>0$ guarantees that all consumers join $A$. For small enough $\varepsilon$ this deviation profit is close to $p_{B}^{1}(s)+p_{B}^{2}(s)$. If $p_{B}^{k}(s) \geq 0 \forall k=1,2$, then $\pi_{B}(s)>0$ implies $p_{B}^{1}(s)+$ $p_{B}^{2}(s)>0$, which implies that the above deviation is profitable for small enough $\varepsilon$. If $p_{B}^{2}(s) \leq 0$, then $\pi_{B}(s)>0$ implies $N_{B}^{1}(s)>0$, but then $N_{A}^{2}(s)>0$ contradicts that every consumer plays a best response in $s$. Therefore $p_{B}^{2}(s)>0$. If $p_{B}^{1}(s)<0$ and $p_{B}^{2}(s)>0$, then $N_{B}^{1}(s)=1$ since $B$ is the unique best response in $s$ after the equilibrium price announcements for side 1 consumers, and therefore $p_{B}^{1}(s)+p_{B}^{2}(s) \geq p_{B}^{1}(s) N_{B}^{1}(s)+p_{B}^{2}(s) N_{B}^{2}(s)=$ $\pi_{B}(s)>0$. This again implies that the above deviation for $A$ is profitable for small enough $\varepsilon$, contradicting that $s$ is a Nash equilibrium. This concludes that $p_{f}^{k}(s) \leq u^{k} \forall k=1,2$ and $f \in\{A, B\}$. Suppose $p_{A}^{k}(s) \neq p_{B}^{k}(s)$ for some $k=1,2$. W.l.o.g. assume $p_{A}^{1}(s)>p_{B}^{1}(s)$. Then $p_{A}^{2}(s) \leq p_{B}^{2}(s)$, otherwise lemma 5.1 implies $N_{A}^{1}(s)=N_{A}^{2}(s)=0$. Suppose first that $N_{A}^{1}(s)=N_{B}^{1}(s)=$ 0 . Then $N_{A}^{2}(s)>0$ and $N_{B}^{2}(s)>0$. This is only compatible with consumers being in equilibrium and firms not getting negative profit if $p_{A}^{2}(s)=p_{B}^{2}(s)=$ 0 . Then $\pi_{B}(s)=0$. Then by lemma 5.1 a deviation $\min \left(u-\varepsilon, p_{A}^{1}(s)-\varepsilon\right),-\varepsilon$ by $B$ for $\varepsilon>0$ guarantees that all consumers join $A$, which for small enough $\varepsilon$ yields positive profit for $B$, contradicting that $s$ is an equilibrium. Suppose next that $N_{A}^{2}(s)=N_{B}^{2}(s)=0$. Then $N_{A}^{1}(s)>0$ and $N_{B}^{1}(s)>0$, which contradicts that $s$ is a Nash equilibrium, since $N_{A}^{2}(s)=N_{B}^{2}(s)=0$ and $p_{A}^{1}(s)>p_{B}^{1}(s)$ implies that given $s_{-1, i} B$ is a better response than $A$ in the subgame following the equilibrium price announcements for every $C_{i}^{1} \in C^{1}$. This concludes that $N_{k}^{1}(s)>0$ for some $k=A, B$ and $N_{k}^{1}(s)>0$ for some $k=A, B$. But then $N_{A}^{1}(s) \leq N_{B}^{1}(s)$ and $N_{A}^{2}(s)>N_{B}^{2}(s)$, otherwise $p_{A}^{1}(s)>p_{B}^{1}(s)$ and $p_{A}^{2}(s) \leq p_{B}^{2}(s)$ imply that some consumers are not playing a best response in $s$. Consider now following two deviations. The first is $\left(p_{B}^{1}(s)-\varepsilon, p_{B}^{2}(s)-\varepsilon\right)$ by $A$, and the second is $\left(p_{A}^{1}(s)-\varepsilon, p_{A}^{2}(s)-\varepsilon\right)$ by $B$. Since $p_{f}^{k}(s) \leq u^{k} \forall k=1,2$ and $f \in\{A, B\}$, lemma 5.1 implies that $s_{i}^{k}\left(p_{B}^{1}(s)-\varepsilon, p_{B}^{2}(s)-\varepsilon, p_{B}^{1}(s), p_{B}^{2}(s)\right)=A$ and $s_{i}^{k}\left(p_{A}^{1}(s), p_{A}^{2}(s), p_{B}^{1}(s)-\right.$ $\left.\varepsilon, p_{B}^{2}(s)-\varepsilon\right)=B \forall k=1,2$ and $i \in[0,1]$. Then the first deviation yields a profit $p_{B}^{1}(s)+p_{B}^{2}(s)-2 \varepsilon$ to $A$, while the second yields $p_{A}^{1}(s)+p_{A}^{2}(s)-2 \varepsilon$ to $B$. The sum of these deviation profits is $p_{A}^{1}(s)+p_{A}^{2}(s)+p_{B}^{1}(s)+p_{B}^{2}(s)-4 \varepsilon$. The sum of the two firms' equilibrium profits is $N_{A}^{1}(s) p_{A}^{1}(s)+N_{A}^{2}(s) p_{A}^{2}(s)+$ $N_{B}^{1}(s) p_{B}^{1}(s)+N_{B}^{2}(s) p_{B}^{2}(s) \equiv \pi^{*}$. Note that $p_{B}^{1}(s)<0$ implies that $N_{A}^{1}(s)+$ $N_{A}^{2}(s)=1$, since then $\emptyset$ is never a best response for any $C_{i}^{1} \in C^{1}$. Similarly, $p_{A}^{2}(s)<0$ implies that $N_{B}^{1}(s)+N_{B}^{2}(s)=1$. Then by $N_{A}^{1}(s) \leq N_{B}^{1}(s)$, $N_{A}^{2}(s)>N_{B}^{2}(s), p_{A}^{1}(s)>p_{B}^{1}(s)$ and $p_{A}^{2}(s) \leq p_{B}^{2}(s)$ it has to hold that 
$N_{A}^{1}(s) p_{A}^{1}(s)+N_{A}^{2}(s) p_{A}^{2}(s)+N_{B}^{1}(s) p_{B}^{1}(s)+N_{B}^{2}(s) p_{B}^{2}(s)<\frac{1}{2}\left(p_{A}^{1}(s)+p_{A}^{2}(s)+\right.$ $\left.p_{B}^{1}(s)+p_{B}^{2}(s)\right)$. The left hand side of this inequality is nonnegative (it is the sum of equilibrium profits), therefore the right hand side is positive, which implies that also $N_{A}^{1}(s) p_{A}^{1}(s)+N_{A}^{2}(s) p_{A}^{2}(s)+N_{B}^{1}(s) p_{B}^{1}(s)+N_{B}^{2}(s) p_{B}^{2}(s)<$ $p_{A}^{1}(s)+p_{A}^{2}(s)+p_{B}^{1}(s)+p_{B}^{2}(s)$. But that implies that for small enough $\varepsilon$ the sum of the two deviation profits above is larger than the sum of the two equilibrium profits, implying that at least one of the deviations is profitable, a contradiction. This concludes that $p_{A}^{k}(s)=p_{B}^{k}(s) \forall k=1,2$. Suppose that $\pi_{A}(s)+\pi_{B}(s)>0$. W.l.o.g. assume $\pi_{A}(s) \geq \pi_{B}(s)$. Then $\pi_{B}(s)<$ $p_{A}^{1}(s)+p_{A}^{2}(s) \leq \pi_{A}(s)+\pi_{B}(s)$ (note that $p_{A}^{k}(s)=p_{B}^{k}(s) \forall k=1,2$, and that $p_{A}^{k}(s)<0$ implies that $\left.C_{i}^{k}(s) \neq \emptyset \forall C_{i}^{k} \in C^{k}\right)$. By lemma 5.1 a deviation $p_{A}^{1}(s)-\varepsilon, p_{A}^{2}(s)-\varepsilon$ by $B$ for $\varepsilon>0$ guarantees that all consumers join $B$, which yields a profit of $p_{A}^{1}(s)+p_{A}^{2}(s)-2 \varepsilon$ to $B$. This implies that the above deviation is profitable for small enough $\varepsilon$, a contradiction. Then $\pi_{A}(s)+\pi_{B}(s) \leq 0$ and since equilibrium profits have to be nonnegative, $\pi_{A}(s)=\pi_{B}(s)=0$. Suppose $p_{A}^{1}(s)+p_{A}^{2}(s)>0$. By lemma 5.1 a deviation $p_{A}^{1}(s)-\varepsilon, p_{A}^{2}(s)-\varepsilon$ by $B$ for $\varepsilon>0$ guarantees that all consumers join $B$, which yields a profit of $p_{A}^{1}(s)+p_{A}^{2}(s)-2 \varepsilon$ to $B$. But for small enough $\varepsilon$ this profit is positive, which contradicts that $\pi_{B}(s)=0$ and that $s$ is an equilibrium. This concludes that $p_{A}^{1}(s)+p_{A}^{2}(s) \leq 0$. Suppose $p_{A}^{1}(s)+p_{A}^{2}(s)<0$. Then $p_{A}^{k}(s)=p_{B}^{k}(s)<0$ for some $k=1,2$. Then $N_{A}^{k}(s)+N_{B}^{k}(s)=1$, since $\emptyset$ is never a best response for any $C_{i}^{k} \in C^{k}$ in the subgame after the equilibrium price announcements. But then $\min \left(\pi_{A}(s), \pi_{B}(s)\right)<0$, contradicting that $s$ is a Nash equilibrium. This concludes that $p_{A}^{1}(s)+p_{A}^{2}(s)=0$. If $p_{A}^{k}(s)=$ $p_{B}^{k}(s)<0$ for some $k=1,2$, then $N_{A}^{k}(s)+N_{B}^{k}(s)=1$. Then nonnegativity of equilibrium profits implies that also $N_{A}^{-k}(s)+N_{B}^{-k}(s)=1$ and that $N_{A}^{1}(s)=N_{A}^{2}(s), N_{B}^{1}(s)=N_{B}^{2}(s)$. If $p_{A}^{1}(s)=p_{B}^{1}(s)=p_{A}^{2}(s)=p_{B}^{2}(s)=$ 0 , then by lemma $5.2 N_{A}^{k}(s)+N_{B}^{k}(s)=1 \forall k=1$,2. As shown above, $N_{A}^{k}(s)+N_{B}^{k}(s)>0 \forall k=1,2$. Then $p_{A}^{k}(s)=p_{B}^{k}(s) \forall k=1,2$ implies $N_{A}^{k}(s)=N_{B}^{k}(s) \forall k=1,2$. This implies $\pi_{A}(s)=\pi_{B}(s)$. If $p_{A}^{k}(s)=p_{B}^{k}(s)<$ 0 for some $k=1,2$, then the above implies that $N_{A}^{k}(s)=N_{B}^{k}(s)=1 / 2$. Then $p_{A}^{1}(s)+p_{A}^{2}(s)=0$ and nonnegativity of equilibrium profits together imply that also $N_{A}^{-k}(s)=N_{B}^{-k}(s)=1 / 2$. If $p_{A}^{1}(s)=p_{B}^{1}(s)=p_{A}^{2}(s)=p_{B}^{2}(s)=0$, then $N_{A}^{j}(s)+N_{B}^{j}(s)=1 \forall j=1,2$ and the fact that $s$ is a Nash equilibrium imply that $N_{A}^{j}(s)=N_{B}^{j}(s)=1 / 2 \forall j=1,2$. QED

Proof of Theorem 5: Lemma 5.3 and lemma 5.4 establish that there are no other coalition perfect equilibria with one or two active firms than those stated in the claim. All that remains to be shown is that there is no coalition perfect equilibrium with no active firm. 
Suppose $N_{A}^{k}(s)+N_{B}^{k}(s)=0 \forall k=1,2$. Then $\pi_{A}(s)=\pi_{B}(s)=0$. If $p_{f}^{k}(s)<0$ for some $k=1,2$ and $f=A, B$, then $N_{A}^{k}(s)+N_{B}^{k}(s)=1$, since $\emptyset$ is a never best response strategy for any $C_{i}^{k} \in C^{i}$, a contradiction. Suppose now that $\exists k \in\{A, B\}$ such that $p_{k}^{j}(s) \geq 0 \forall j=1,2$ and $p_{j}^{l}(s)>0$ for some $l \in\{1,2\}$. W.l.o.g. assume $p_{A}^{1}(s)>0$ (and $p_{A}^{2}(s) \geq 0$ ). By lemma 5.1 the deviation $\min \left(u^{1}-\varepsilon, p_{A}^{1}(s)-\varepsilon\right), \min \left(u^{2}-\varepsilon, p_{A}^{2}(s)-\varepsilon\right)$ by $B$ for $\varepsilon>0$ guarantees that every consumer joins $B$, and it yields strictly positive profit for small enough $\varepsilon$, a contradiction. If $p_{k}^{j}(s)=0 \forall j=1,2$ and $k=A, B$, then $N_{A}^{j}(s)+N_{B}^{j}(s)=1 \forall j=1,2$ by lemma 5.3 . This concludes that if $s$ is a coalition perfect equilibrium, then it cannot be that $N_{A}^{j}(s)+N_{B}^{j}(s)=0$ $\forall j=1,2$. QED

Proof of Theorem 6 W.l.o.g. assume that $k=1$ (the other case is perfectly symmetric), so $u^{1}<u^{2}$.

By Theorem 5 if $N_{k}^{1}(s)+N_{k}^{2}(s)>0$ for some $k \in\{A, B\}$, then $p_{k}^{1}(s)=$ $-p_{k}^{2}(s)$ and $p_{k}^{l}(s) \leq u^{l} \forall l=1,2$. Furthermore, $\pi_{A}(s)=\pi_{B}(s)=0$.

Assume $N_{A}^{1}(s)+N_{A}^{2}(s)>0$ and suppose $p_{A}^{1}(s)>u^{1}-u^{2}$. Consider the deviation $p_{A}^{1}(s)-u^{1}-\varepsilon, u^{2}-\varepsilon$ by $B$ for $\varepsilon>0$. In the subgame following the deviation $B$ is a strictly dominant strategy for every $C_{i}^{1} \in C^{1}$, therefore it is the only rationalizable strategy. But then $B$ is the only rationalizable strategy in the subgame for every $C_{i}^{2} \in C^{2}$ too. Therefore after the above deviation $B$ 's profit in $s$ is $p_{A}^{1}(s)-u^{1}+u^{2}-2 \varepsilon$. Since $p_{A}^{1}(s)>u^{1}-u^{2}$, this profit is strictly positive for small enough $\varepsilon$, contradicting that $s$ is an equilibrium. A perfectly symmetric argument shows that it cannot be that $N_{B}^{1}(s)+N_{B}^{2}(s)>0$ and $p_{B}^{1}(s)>u^{1}-u^{2}$. QED

Proof of Theorem 7 Let $s$ be a coalition perfect equilibrium.

Suppose first that $N_{k}^{j}(s)=0$ for some $j \in\{1,2\}$ and $k \in\{A, B\}$. W.l.o.g. assume $k=A$ and $j=1$. Then either $N_{A}^{1}(s)=N_{A}^{2}(s)=0$ or $N_{A}^{2}(s)>0$ and $p_{A}^{1}(s)=0$. In either case $\pi_{A}=0$ and then by the starting assumption $\pi_{B}(s)>0$. Let $\widehat{C}=\left\{C_{i}^{j}: c_{i}^{j}(s)=B\right\}$. Note that $p_{B}^{j}(s)<0$ for some $j \in\{1,2\}$ implies that $C^{j} \subset \widehat{C}$. Consider now deviation $\left(p_{B}^{1}(s)-\varepsilon, p_{B}^{2}(s)-\varepsilon\right)$ for $\varepsilon>0$ by $A$. Similar arguments as in Lemma 5.1 establish that in the subgame after this deviation $A$ is the unique coalitionally rationalizable strategy for every $C_{i}^{j} \in \widehat{C}$. But then for small enough $\varepsilon$ the deviation is profitable, a contradiction. Therefore $N_{k}^{j}(s)>0 \forall j \in\{1,2\}$ and $k \in$ $\{A, B\}$.

If $p_{A}^{j}(s)>p_{B}^{j}(s) \forall j=1,2$ then similar arguments as in 5.1 establish that $N_{A}^{1}(s)+N_{A}^{2}(s)=0$, contradicting the above result. Similarly it cannot 
be that $p_{A}^{j}(s)<p_{B}^{j}(s) \forall j=1,2$.

Consider now $p_{A}^{j}(s)=p_{B}^{j}(s) \forall j=1,2$. Let $\widehat{C}=\left\{C_{i}^{j}: c_{i}^{j}(s) \neq \emptyset\right\}$. There exists $k \in\{A, B\}$ such that $\pi_{k}(s) \leq\left(\pi_{1}(s)+\pi_{2}(s)\right) / 2>0$. W.l.o.g. assume $k=A$. Consider deviation $\left(p_{B}^{1}(s)-\varepsilon, p_{B}^{2}(s)-\varepsilon\right)$ by $A$. Similar arguments as in Lemma 5.1 establish that in the subgame after this deviation $A$ is the unique coalitionally rationalizable strategy for every $C_{i}^{j} \in \widehat{C}$. Therefore if $\varepsilon$ is small enough then after this deviation $A$ 's profit is larger than $\left(\pi_{1}(s)+\right.$ $\left.\pi_{2}(s)\right) / 2$ (note that $p_{B}^{j}(s)<0$ for some $j=1,2$ implies that $C^{j} \subset \widehat{C}$ ), a contradiction.

Finally, notice that if $p_{A}^{j}(s) \leq p_{B}^{j}(s)$ for some $j \in\{1,2\}$, then $N_{B}^{j}(s)>0$ and the assumption that $s$ is a Nash equilibrium imply that $N_{B}^{3-j}(s) \geq$ $N_{A}^{3-j}(s)$. If $p_{A}^{j}(s)<p_{B}^{j}(s)$ for some $j \in\{1,2\}$, then $N_{B}^{j}(s)>0$ and the assumption that $s$ is a Nash equilibrium imply that $N_{B}^{3-j}(s)>N_{A}^{3-j}(s)$. Similarly if $p_{B}^{j}(s) \leq p_{A}^{j}(s)$ (correspondingly $p_{B}^{j}(s)<p_{A}^{j}(s)$ ) for some $j \in\{1,2\}$, then $N_{B}^{3-j}(s) \leq N_{A}^{3-j}(s)$ (correspondingly $N_{B}^{3-j}(s)<N_{A}^{3-j}(s)$ ). QED

Lemma 8.1 Let $G^{c}=\left(C, S^{c}, u^{c}\right)$ be the subgame following price announcements $\left(p_{A}^{1}, p_{A}^{2}, p_{B}^{1}, p_{B}^{2}\right)$. If $p_{A}^{j}<p_{B}^{j} \forall j=1,2$ then $B$ is not coalitionally rationalizable in $G^{c}$ for any $C_{i}^{j} \in C$. Furthermore, if $A$ is rationalizable for some $C_{i}^{j} \in C$ in a subgame following price announcements $\left(q_{A}^{1}, q_{A}^{2}, p_{B}^{1}, p_{B}^{2}\right)$ where $q_{A}^{1}>p_{A}^{1}$ and $q_{A}^{2}>p_{A}^{2}$ then $A$ is the unique coalitionally rationalizable strategy in $G^{c}$ for $C_{i}^{j}$.

Similarly if $p_{B}^{j}<p_{A}^{j} \forall j=1,2$ then $A$ is not coalitionally rationalizable in $G^{c}$ for any $C_{i}^{j} \in C$. Furthermore, if $B$ is rationalizable for some $C_{i}^{j} \in C$ in a subgame following price announcements $\left(p_{A}^{1}, p_{A}^{2}, q_{B}^{1}, q_{B}^{2}\right)$ where $q_{B}^{1}>p_{B}^{1}$ and $q_{B}^{2}>p_{B}^{2}$ then $B$ is the unique coalitionally rationalizable strategy in $G^{c}$ for $C_{i}^{j}$.

Proof of Lemma 8.1 Analogous to the proof of Lemma 5.1, therefore ommitted.

Proof of Theorem 8 Let $\Delta=\min \left(\frac{\sup _{k} u_{k}^{1}}{\inf _{j, k} u_{k}^{1}}, \frac{\sup _{k} u_{k}^{2}}{\inf _{j, k} u_{k}^{2}}\right)$ and let $s$ be a coalition perfect equilibrium. By the starting assumption $\Delta \leq 4 / 3$. Assume the theorem does not hold for $s$. Then by Theorem $7 \exists j \in\{1,2\}$ such that $p_{A}^{j}(s)<p_{B}^{j}(s), N_{A}^{j}(s) \geq N_{B}^{j}(s)$ and $p_{A}^{-j}(s) \geq p_{B}^{-j}(s), N_{A}^{-j}(s)<N_{B}^{-j}(s)$. For every $j \in\{1,2\}$ let $\inf _{k} u_{k}^{j} \equiv l^{j}$. If $p_{k}^{j}(s) \leq l^{j} \forall k \in\{A, B\}$ and $j \in\{1,2\}$ then an analogous proof to the proof of Lemma 5.4 establishes that there is a profitable deviation for at least one firm, contradicting that $\mathrm{s}$ is a coalition perfect equilibrium. The same holds if $p_{k}^{j}(s) \geq 0 \forall k \in\{A, B\}$ and $j \in\{1,2\}$. It is straightforward to show that it cannot be that for some 
$k \in\{A, B\}$ it holds that $p_{k}^{j}(s)>l^{j} \forall j \in\{1,2\}$. Below we consider the remaining possibilities. Consider first the case that for some $k \in\{A, B\}$ and $j \in\{1,2\}$ it holds that $p_{k}^{j}(s)>l^{j}, p_{k}^{-j}(s)<0$ and $0 \leq p_{-k}^{1}(s), p_{-k}^{2}(s)$. Since $\sup _{k} u_{k}^{j} \leq \Delta l^{j} \leq \frac{4}{3} l^{j}$ and $p_{k}^{j}(s)>l^{j}$, for $N_{k}^{j}(s)>0$ it has to be that $N_{k}^{-j}(s)>\frac{3}{4}$. Furthermore, $p_{k}^{j}(s)>p_{-k}^{j}(s)$ implies $N_{k}^{j}(s) \leq \frac{1}{2}$, and $\sup _{k} u_{k}^{j} \leq \Delta l^{j} \leq \frac{4}{3} l^{j}$ implies $p_{k}^{j}(s)<\frac{4}{3} l^{j}$. Therefore $\pi_{k}(s) \leq \frac{2}{3} l^{j}+\frac{3}{4} p_{k}^{-j}(s)$. Then $\pi_{k}(s) \geq 0$ implies $l^{j}+p_{k}^{-j}(s)>\frac{2}{3} l^{j}+\frac{3}{4} p_{k}^{-j}(s)$ and therefore $\pi_{k}(s)<$ $l^{j}+p_{k}^{-j}(s)$. But note that $-k$ can get a profit arbitrarily close to $l^{j}+p_{k}^{-j}(s)$ by deviating to price announcements $\left(l^{j}-\varepsilon, p_{k}^{-j}(s)-\varepsilon\right)$ for small enough $\varepsilon>0$ (since by Lemma 8.1 after that price announcement all consumers join $B$ ). So if $\pi_{-k}(s) \leq \pi_{k}(s)$ then $-k$ has a profitable deviation from $s$. On the other hand note that $k$ can get a profit arbitrarily close to $l^{j}+p_{k}^{-j}(s)$ by deviating to price announcements $\left(p_{-k}^{1}(s)-\varepsilon, p_{-k}^{2}(s)-\varepsilon\right)$ for small enough $\varepsilon>0$. So if $\pi_{-k}(s)>\pi_{k}(s)$ then $k$ has a profitable deviation from $s$. This concludes that $s$ cannot be a coalition perfect equilibrium, a contradiction. Consider now the case that for some $k \in\{A, B\}$ and $j, h \in\{1,2\}$ it holds that $p_{k}^{j}(s)>l^{j}$ and $0>p_{-k}^{h}(s)$. Just like in the previous case, it has to be that $N_{k}^{-j}(s)>\frac{3}{4}$ and therefore $N_{-k}^{-j}(s)<\frac{1}{4}$. Then $\sup _{k} u_{k}^{j} \leq \Delta l^{j} \leq \frac{4}{3} l^{j}$ implies $p_{-k}^{j}(s)<\frac{1}{3} l^{j}$. Then $0>p_{-k}^{h}(s)$ and $\frac{4}{3} l^{j}>p_{-k}^{-h}(s)$ imply that $\pi_{-k}(s)<\frac{1}{3} l^{j}$. Since $N_{k}^{j}(s) \leq \frac{1}{2}$ and $p_{k}^{j}(s) \leq \frac{4}{3} l^{j} N_{k}^{-j}(s)$ and $\pi_{k}(s) \geq 0$, it holds that $\frac{2}{3} l^{j} N_{k}^{-j}(s)+p_{k}^{-j}(s) N_{k}^{-j}(s) \geq 0$, therefore $p_{k}^{-j}(s) \geq-\frac{2}{3} l^{j}$. Therefore $l^{j}+$ $p_{k}^{-j}(s) \geq \frac{1}{3} l^{j}$. But note that $-k$ can get a profit arbirarily close to $l^{j}+p_{k}^{-j}(s)$ by deviating to price announcement $\left(l^{j}-\varepsilon, p_{k}^{-j}(s)-\varepsilon\right)$ for small enough $\varepsilon>0$. This concludes that $s$ cannot be a coalition perfect equilibrium, a contradiction. QED 


\section{References}

[1] AMBRUS, A. (2002): "Coalitional rationality" (Mimeo, Princeton University).

[2] AMBRUS, A. (2003), "Dynamic coalitional agreements in multi-stage games" (Mimeo, Princeton University and Yale University).

[3] ARMStrong, M. (2002), "Competition in Two-Sided Markets" (Mimeo, UCL).

[4] BAUMOL, W.J., PANZAR, J. and WILliG, R. (1982), "Contestable Markets and the Theory of Industry Structure", (New York: Harcourt).

[5] BENTAL, B and SPIEGEL, M. (1995), "Network Competition, Product Quality, and Market Coverage in the Presence of Network Externalities", Journal of Industrial Economics, 43, 197-208.

[6] BERnHEIM, B.D., PELEG, B. and WHINSTON, M.D. (1987), "Coalition-Proof Nash Equilibria I. Concepts", Journal of Economic Theory, 42, 1-12.

[7] CAillaud, B. and Jullien, B. (2003), "Chicken \& Egg: Competition Among Intermediation Service Providers", Rand Journal of Economics, 34, 309-328.

[8] CAILlaud, B. and JULliEN, B. (2001), "Competing Cybermediaries", European Economic Review, 45, 797-808.

[9] DAMIANO, E. and LI, H. (2003a), "Price discrimination in matching markets" (Mimeo, University of Toronto).

[10] DAMIANO, E. and LI, H. (2003b), "Competing Matchmaking" (Mimeo, University of Toronto).

[11] ECONOMIDES, N. (1996), "The Economics of Networks", International Journal of Industrial Organization, 14, 673-699

[12] ECONOMIDES, N. and SKRZYPACZ, A. (2003), "Standards Coalitions Formation and Market Structure in Network Industries" (Stern School of Business, N.Y.U. Working Paper).

[13] ELliSON, G., FUDENBERG, D. and MOBIUS, M. (2002), "Competing Auctions" (Mimeo, MIT and Harvard University). 
[14] ELLISON, G. and FUDENBERG, D.(2003), "Knife-Edge or Plateau: When Do Market Models Tip?" (Mimeo, Harvard University and MIT).

[15] FARRELL, J. and KLEMPERER, P. (2001), "Coordination and LockIn: Competition with Switching Costs and Network Effects", (Mimeo, University of California at Berkeley and Nuffield College, Oxford University).

[16] INNES R. and SEXTON, R. (1993), "Customer Coalitions, Monopoly Price Discrimination, and Generic Entry Deterrrence", European Economic Review, 37, 1569-1597.

[17] JULLIEN, B. (2001), "Competing in Network Industries: Divide and Conquer", (Mimeo, IDEI Tolouse).

[18] KATZ, M. and SHAPIRO, C. (1994), "System Competition and Network Effects", Journal of Economic Perspectives, 8, 93-115.

[19] MASKIN, E and RILEY, J. (1984), "Monopoly and Incomplete Information", RAND Journal of Economics, 15, 171-196.

[20] MUSSA, M and ROSEN, S. (1978), "Monopoly and Product Quality", Journal of Economic Theory, 18, 301-317.

[21] ROCHET, J.C. and TIROLE, J. (2002), "Cooperation among Competitors: Some Economics of Payment Card Associations", RAND Journal of Economics, 33, 549-570.

[22] ROCHET, J.C. and TIROLE, J. (2003), "Platform Competition in Two-Sided Markets", Journal of the European Economic Association, 1, 990-1029.

[23] SALANIE, B. (1997), "The economics of contracts: A primer ", (Cambridge: MIT Press).

[24] SEGAL, I. (2003), "Coordination and Discrimination in Contracting with Externalities: Divide and Conquer?", Journal of Economic Theory 113, 147-327.

[25] VARIAN, H. (1988), "Price Discrimination", in Schmalensee, R. and R. Willig (editors) Handbook of Industrial Organization, (Amsterdam, Elsevier).. 